\title{
Star polymers in good solvents from dilute to concentrated regimes: Crossover approach
}

\author{
L.Lue $^{1}$, S.B.Kiselev ${ }^{2}$ \\ 1 Department of Chemical Engineering, UMIST, \\ Manchester M60 1QD, United Kingdom \\ 2 Chemical Engineering Department, Colorado School of Mines, \\ 1500 Illinois St., Golden, CO 80401-1887, USA
}

Received September 12, 2001

\begin{abstract}
An introduction is given to the crossover theory of the conformational and thermodynamic properties of star polymers in good solvents. The crossover theory is tested against Monte Carlo simulation data for the structure and thermodynamics of model star polymers. In good solvent conditions, star polymers approach a "universal" limit as $N \rightarrow \infty$; however, there are two types of approach towards this limit. In the dilute regime, a critical degree of polymerization $N^{*}$ is found to play a similar role as the Ginzburg number in the crossover theory for critical phenomena in simple fluids. A rescaled penetration function is found to control the free energy of star polymer solutions in the dilute and semidilute regions. This equation of state captures the scaling behaviour of polymer solutions in the dilute/semidilute regimes and also performs well in the concentrated regimes, where the details of the monomer-monomer interactions become important.
\end{abstract}

Key words: star polymer, computer simulation, renormalization group, polymer field theory

PACS: $61.25 . \mathrm{Hq}$

\section{Introduction}

Star polymers are macromolecules consisting of a number $f$ (arm number) of linear polymer chains tethered to a central core. As the number of the arms and the radius of the core increase, they exhibit properties very different from linear polymers. With a microscopic core and $f \gg 1$, star polymers in different solvents exhibit the static properties of colloidal particles [1-3] (including micelles [4,5]), gel- [6] and solid-like $[7,8]$ structures. If the core size is much larger than characteristic size of the individual arm, such an entity is called a "nanoparticle", and its properties are dominated by the cross-linked nanometer-sized core [9]. The unique structural and 
dynamical properties of star polymers make them very attractive for investigators (see also [10-12]). This subject has become a very active research field for scientists with a diverse range backgrounds, including physicists who are interested in the universal scaling properties and crossover behaviour of polymer solutions in the bulk and at an interface, as well as physical chemists investigating in association colloids and microemulsions. During the last 10 years, there have been a vast number of theoretical [13-33], computer simulation [34-60], and experimental studies [2-8,61-68] of the static properties of star polymers at different solvent conditions. The range of the topics of these researches is extremely wide. It includes the conformation properties of isolated star polymers $[18,27,37,42,49,50,52-54]$ and dilute star polymers solutions in good solvents $[19,24,30,41,43-46,48,55,56,64-66]$, the second virial coefficient $[45,46,48,55,56,67,68]$, equation of state and thermodynamic properties of star polymers in semidilute and concentrated regimes [14,22,25,28,62,63], freezing of star polymers [33,58-60], adsorption [20,21,23], and star polymers grafted to a wall $[29,31,46]$. A special place in these studies occupy star polymers at theta conditions [13,15-17,19,26,32,36,38-41,43,54,57,63,67-69]. There has also been a large number of studies of the dynamics of star polymers, which include the relations between structure and dynamics [70-78], phase separation [79] and self-assembly kinetics [80], relaxation phenomena [81-85], viscosity [86-88] and diffusion [89-93], rheological behaviour [94,95], viscoelastic properties [96-98], and glass transition [99].

As with linear polymers, three major regions can be identified for star polymers, depending on the nature of the interactions between the monomer segments: (i) poor conditions, (ii) $\theta$ solvent conditions, and (iii) good solvent conditions. The poor solvent conditions correspond to the situation when the attractive interactions make a major contribution to the interactions between the monomer segments of the polymer. At these conditions, the details of the monomer-monomer interactions affect the properties of the polymer. In these situations, the polymer exists as a collapsed globule.

As the temperature increases, the attractive interactions become less and less significant and the repulsive interactions eventually cancel, or balance out, the effect of the attractive interactions. In this situation, the macromolecule displays characteristics very similar to a random walk (RW), where there are no interactions between the various segments. These conditions are referred to as $\theta$ conditions. The $\theta$ region separates the poor solvent region from the good solvent region, and its size is fairly small for large macromolecules, varying as $\sim M^{-1 / 2}$, where $M$ is the polymer molecular weight.

In good solvent conditions, when the monomer-monomer interactions are primarily dominated by excluded volume (EV) interactions and the attractive interactions play only a minor role (in real systems, this typically occurs at high temperatures), many properties of the macromolecule become "universal". That is, the properties become independent of the details of the monomer interactions and depend only on the general features of the macromolecule, such as its molecular weight and architecture. As we will discuss later, there are, in general, two good solvent regimes. The infinite molecular weight $(M \rightarrow \infty)$ limit of both these regimes are identical; 
however, the "direction of approach" to this limit is different.

The objective of this paper is to give an introduction into the crossover approach to the describing of static properties of star polymers in good solvents. This approach is based on the fundamental results of the renormalization group (RG) theory $[100$, 101] and during the last few years has been successfully applied to the describing of the thermodynamic properties of such different systems as one-component fluids and fluid mixtures [102-107], ionic solutions [108-110], polymer blends [111-114], and microemulsions [115] near the second-order phase transitions, as well as to the conformation properties of linear [116,117] and star [118] polymers.

The remainder of this paper is organized as follows. In section 3, we discuss the properties of dilute star polymer solutions. In section 4 , we discuss the semidilute regime. In section 5, we discuss the concentrated regime.

\section{Model star polymer}

As mentioned in the introduction, there are many computer simulation studies on the properties of star polymers. As a result, several different molecular models for star polymers have been developed and studied, including lattice models on various types of lattices (e.g., tetrahedral [119] or simple cubic $[45,47]$ ) and continuum models with various types of monomer-monomer interactions (e.g., Lennard-Jones $[34,49,55]$ or hard sphere $[56,118]$ ), and bonding constraints (e.g., Gaussian bonds $[34,56]$ or rigid bonds $[118])$.

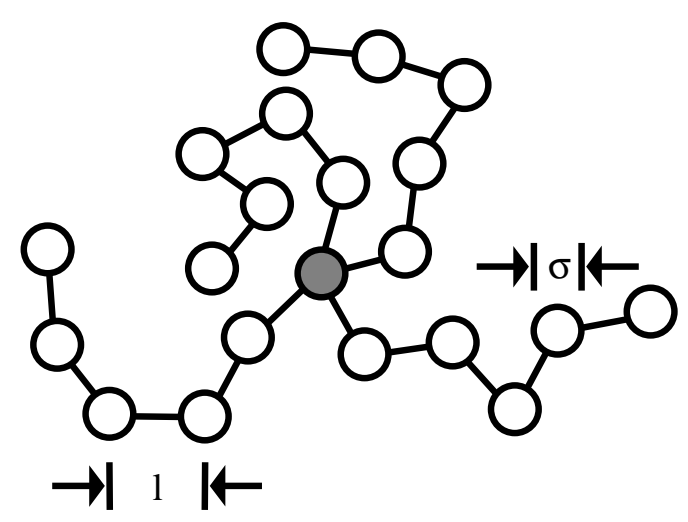

Figure 1. Schematic drawing of a fourarm $(f=4)$ star polymer with $N=5$ spheres per arm. The diameter of the spheres is $\sigma$, and the bond length is $l$. The shaded sphere is the central "core" sphere.
In this paper, we will focus primarily on a simple model star polymer composed of rigidly bonded hard spheres. A schematic drawing is given in figure 1. All of the spheres are of diameter $\sigma$. The $f$ arms of the star polymer are all attached to a central "core" sphere. Each arm consists of $N$ spheres, and the bond length between each of the spheres is kept rigidly fixed at $l$. The angles between the bonds, however, are allowed to freely vary. The spheres interact with each other only through excluded volume (EV) effects. That is, the spheres do interact with each other if they do not overlap; however, if they do overlap, there is an infinitely strong repulsion. Because the monomers interact only repulsively, these polymers are always in the good solvent regime.

As the molecular weight of the star polymer increases, the properties approach a universal limiting form which is independent of the details of the monomer-monomer 
interactions, but is dependent on the overall number of arms. The strength of the excluded volume interactions can be adjusted by changing the hard-sphere diameter. Without EV interaction $(\sigma / l=0$ in figure 1$)$, a star-shaped macromolecule corresponds to the so-called ideal polymer chain which is mathematically equivalent to the random walk model $[120,121]$.

Because this model lacks attractive interactions between its monomer segments, it does not exhibit the complications that can be associated with polymers in near $\theta$-solvent conditions. These effects may have relevance in real polymers. However, our concern is only with polymers in the good solvent regime, away from the $\theta$ point. In this limit, the details of the monomer-monomer should not be significant.

\section{Dilute star polymers}

At dilute concentrations, the size of the star polymers is much smaller than the typical spacing between different star polymers. As a result, the polymers may be treated as distinct entities. In this section, we first describe the structure of star polymers at dilute concentrations. Then, we discuss the interaction between star polymers. Finally, we describe the crossover description of these systems.

\subsection{Structure}

The conformational properties of a polymer molecule can be characterized by many different quantities. Here, we only mention a few most important ones. The mean square end-to-end $(f=1)$, or center-to-end for star-shaped polymers $(f \geqslant 2)$, distance $[120,121]$ is defined as

$$
\left\langle R^{2}\right\rangle=\left\langle\left(\mathbf{r}_{0}-\mathbf{r}_{N}\right)^{2}\right\rangle,
$$

where $\mathbf{r}_{0}$ is the position of the core of the star polymer, and $\mathbf{r}_{N}$ is the position of the end-site of one of the arms of the star polymer.

The mean square radius of gyration $\left\langle R_{\mathrm{g}}^{2}\right\rangle$ yields an overall size of a polymer. It is defined as $[120,121]$

$$
\left\langle R_{\mathrm{g}}^{2}\right\rangle=\frac{1}{2 M^{2}}\left\langle\sum_{i=0}^{M} \sum_{j=0}^{M}\left(\mathbf{r}_{i}-\mathbf{r}_{j}\right)^{2}\right\rangle=\frac{1}{M}\left\langle\sum_{i=1}^{M}\left(\mathbf{r}_{i}-\mathbf{r}_{\mathrm{CM}}\right)^{2}\right\rangle,
$$

where $M=N f+1$ is the total number of interaction sites (spheres) in the star polymer, and $\mathrm{r}_{\mathrm{CM}}$ is the position of the center of mass of the polymer.

The asphericity of $A$ provides a description of the shape of a polymer. It is defined as $[122,123]$

$$
A=1-\frac{3}{M} \frac{\langle W\rangle}{\left\langle R_{\mathrm{g}}^{2}\right\rangle}
$$

where

$$
W=\sum_{i=0}^{M} \sum_{j=0}^{M}\left[\left(\Delta x_{i}\right)^{2}\left(\Delta y_{j}\right)^{2}+\left(\Delta y_{i}\right)^{2}\left(\Delta z_{j}\right)^{2}+\left(\Delta x_{i}\right)^{2}\left(\Delta z_{j}\right)^{2}\right]
$$


and $\Delta x_{i}, \Delta y_{i}$, and $\Delta z_{i}$ are the Cartesian components of the vector $\mathbf{r}_{i}-\mathbf{r}_{\mathrm{CM}}$ (i.e., the displacement of monomer $i$ from the center of mass of the polymer). For rod-like molecules $A=1$, and for the spherically symmetric molecules $A=0$.

For three-dimension ideal star polymers the following formula was derived by Wei and Eichinger [124] in the limit of the infinite chain $(N \rightarrow \infty)$

$$
A(f)=\frac{10(15 f-14)}{15(f-2)^{2}+4(15 f-14)} .
$$

For large values of $f$ the asphericity vanishes like $\frac{10}{9} f^{-1}$, which is in good agreement with the results of a renormalization group (RG) study [30] and Monte Carlo (MC) simulation [49]. There is no theoretical expression for asphericity of stars with EV interaction, but MC simulations [30,37,49,54,125] indicate that, similar to ideal star polymers, the asphericity of stars with EV also vanishes with increasing of $f$.

The statistical distribution of the end-to-end distance and of the radius of gyration of an ideal linear polymer is Gaussian [120,121]. The center-to-end distance and the radius of gyration of an ideal star polymer also obey the Gaussian distribution, to a high degree of accuracy $[43,52,126]$. As a consequence, the mean-square center-toend distance and the mean-square radius of gyration of a star-shaped macromolecule without EV, similar to an ideal chain molecule, are linear in $N$. The difference between an ideal linear polymer and an ideal star polymer appears in the dependence of the center-to-end distance and radius of gyration on $f$.

In the blob model of Daoud and Cotton [127] for star molecule without EV $(v=0$ in table $\mathrm{I}$ in [127])

$$
\left\langle R_{\mathrm{g}}^{2}(N, f)\right\rangle_{0} \propto N f^{1 / 2} l^{2}, \quad\left(N \gg f^{1 / 2}\right) .
$$

Equation (6) exhibits an "ideal" dependence on $N$, but, because of the factor $f^{1 / 2}$, the radius of gyration for star-shaped molecule is in fact larger than for the linear chain. For the ratio

$$
g(f)=\frac{\left\langle R_{\mathrm{g}}^{2}(N, f)\right\rangle}{\left\langle R_{\mathrm{g}}^{2}(N, f=1)\right\rangle}
$$

at $N=$ const, the Daoud-Cotton theory without EV yields via equation $(6) g(f) \propto$ $f^{1 / 2}$, while in the RWM [128] and RG theory in four dimension $(d=4$ and $\epsilon=0$ in equation (4.4) in [129]) which is physically equivalent to the RWM [120], $g(f)=$ $(3 f-2) / f^{2}$.

The statistical distribution of the end-to-end distance and of the radius of gyration of star polymers with EV interactions $(\sigma>0)$ and $N \gg 1$ is Kuhnian [121], rather than Gaussian, and the mean square center-to-end distance $\left\langle R^{2}(N, f)\right\rangle$ and the mean square radius of gyration $\left\langle R_{\mathrm{g}}^{2}(N, f)\right\rangle$ as $N$ and $f \rightarrow \infty$ behave like $[43,125,127,130]$

$$
\left\langle R^{2}(N, f)\right\rangle \propto\left\langle R_{\mathrm{g}}^{2}(N, f)\right\rangle \propto N^{2 \nu} f^{1-\nu} l^{2},
$$

where $\nu$ is the universal correlation-length exponent, which is equal to 0.588 for a good solvent in three dimensions [131]. Since $2 \nu>1$, the most obvious effect 
of excluded volume interactions is the swelling of a polymer chain. The swelling parameter $\alpha$, or expansion factor, [132]

$$
\alpha^{2}(N, f)=\frac{\left\langle R_{\mathrm{g}}^{2}(N, f)\right\rangle}{\left\langle R_{\mathrm{g}}^{2}(N, f)\right\rangle_{0}}
$$

which for a polymer chain with EV interaction is always greater than one [121], quantitatively specifies the role of volume interactions. In accordance with equations (6) and (8), for a star polymer with EV interaction $\alpha^{2} \propto N^{2 \nu-1} \approx N^{0.176}$ as $N \rightarrow \infty$ (with $f$ held constant), which is in good agreement with the computer simulation results [133].

The $f$-dependence of the swelling parameter for a star polymer with excluded volume interactions, however, is poorly predicted by Daoud-Cotton model, as compared to simulation results. At fixed $N$, the Daoud-Cotton model yields $\alpha^{2} \propto f^{(1-2 \nu) / 2}$ (or equivalently, the swelling parameter vanishes as $f^{-0.08}$, for large values of $f$ ), while MC simulation results [39] and experimental data [18,63,134,135] indicate that $\alpha^{2}$ increases with increasing of $f$. The RG calculations of Miyake and Freed [129] ( $d=3$ and $\epsilon=1$ in equation (4.4) in [129]) yield qualitatively better predictions for the swelling parameter $\alpha^{2}$ and ratio $g(f)$, which predicts that at constant $N, \alpha^{2} \propto g(f) \propto f$ at $f \gg 1$, while at constant molecular weight, the ratio $g(f) \propto$ const + const $\cdot f^{-1}$ at $f \geqslant 2$, in a qualitative agreement with MC simulations $[37,55,125]$.

In addition, theories have been developed $[136,118]$ to describe a crossover of star polymers from the Gaussian (ideal) to Kuhnian (EV) scaling regimes. In the theory developed by Lue and Kiselev [118], the mean-square center-to-end distance for star polymers was expressed as a universal crossover function of the parameter $\bar{N}=f N / N^{*}$. In this theory, a critical degree of polymerization $N^{*}$, to be specified below, was found to play a similar role as the Ginzburg number in second-order phase transitions $[100,101]$. Polymers with $1 \ll f N \ll N^{*}(\bar{N} \ll 1)$ exhibit Gaussian statistics, and polymers with $N^{*} \ll f N(\bar{N} \gg 1)$ are in the Kuhnian scaling regime. A crossover from Gaussian statistics to the Kuhnian regime is observed when $f N \simeq$ $N^{*}(\bar{N} \simeq 1)$. In this approach, the critical degree of polymerization $N^{*}$ for the hardsphere polymers depends only on the ratio $\sigma / l$. Therefore, if the parameters $f, N$, and $\sigma / l$ are known, all other properties of star polymer can be predicted. In figure 2 , we plot the dimensionless ratio

$$
\bar{R}^{2}(N, f)=\frac{\left\langle R^{2}(N, f)\right\rangle}{\left\langle R^{2}(N, f=1)\right\rangle_{0}}
$$

calculated with the crossover expression obtained in our previous works for linear chains $[116,117]$ in comparison with MC simulation data [118] for star polymers with $0.1 \leqslant \sigma / l<0.4472$ and $f \leqslant 18$. Excellent agreement between theory and MC simulation data is observed. This theory and its application to the prediction of other properties of star polymers will be considered in more detail in the following sections. 


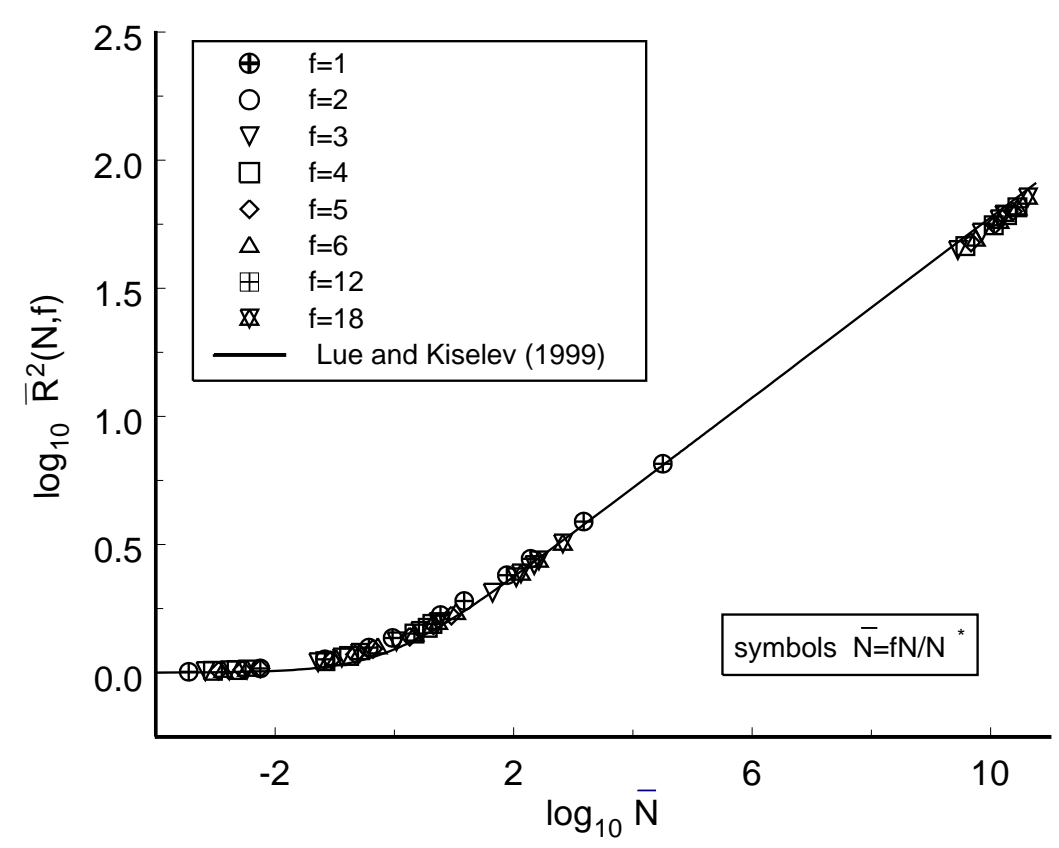

Figure 2. Dimensionless ratio $\bar{R}^{2}(N, f)$ defined by equation (10) for star polymers as a function of the rescaled degree polymerization $\bar{N}$ : (i) simulation data from [118] (symbols), (ii) calculated values for linear polymers from [117] (line).

\subsection{Penetration function}

As the polymer concentration increases, star polymers in good solvents can no longer be considered as ideal solutions, and interactions between separate molecules are needed to be taken into account. In the situation where the polymer concentration is non-vanishing, but the fraction of space occupied by the monomers is still low, the osmotic pressure $\Pi$ can be expanded in powers of $c_{\mathrm{p}}$

$$
\frac{\Pi}{N_{\mathrm{A}} k_{\mathrm{B}} T}=\frac{c_{\mathrm{p}}}{M}+B_{2} c_{\mathrm{p}}^{2}+\mathcal{O}\left(c_{\mathrm{p}}^{3}\right)+\cdots .
$$

where $k_{\mathrm{B}}$ is the Boltzmann constant, $N_{\mathrm{A}}$ is Avogadro's number, $T$ is the absolute temperature of the system, $c_{\mathrm{p}}$ is the number density of polymer molecules in the system, and $B_{2}$ is the second virial coefficient between two polymers.

The penetration function $\Psi$ is often used to quantitatively characterize the influence of intermolecular interactions in dilute solutions. As we will demonstrate later, it also plays a role in determining the properties of star polymer solutions in the semi-dilute regime. It is defined as

$$
\Psi=\left(\frac{d}{12 \pi}\right)^{d / 2} \frac{2 B_{2}}{\left\langle R_{\mathrm{g}}^{2}\right\rangle^{d / 2}},
$$

where $d$ is the dimensionality of the system, and $\left\langle R_{\mathrm{g}}^{2}\right\rangle$ is the mean-square radius of gyration of the polymer at infinite dilution.

The penetration function is a ratio of the volume of space a molecule excludes from other molecule to the volume of space that a molecule occupies. The larger the 

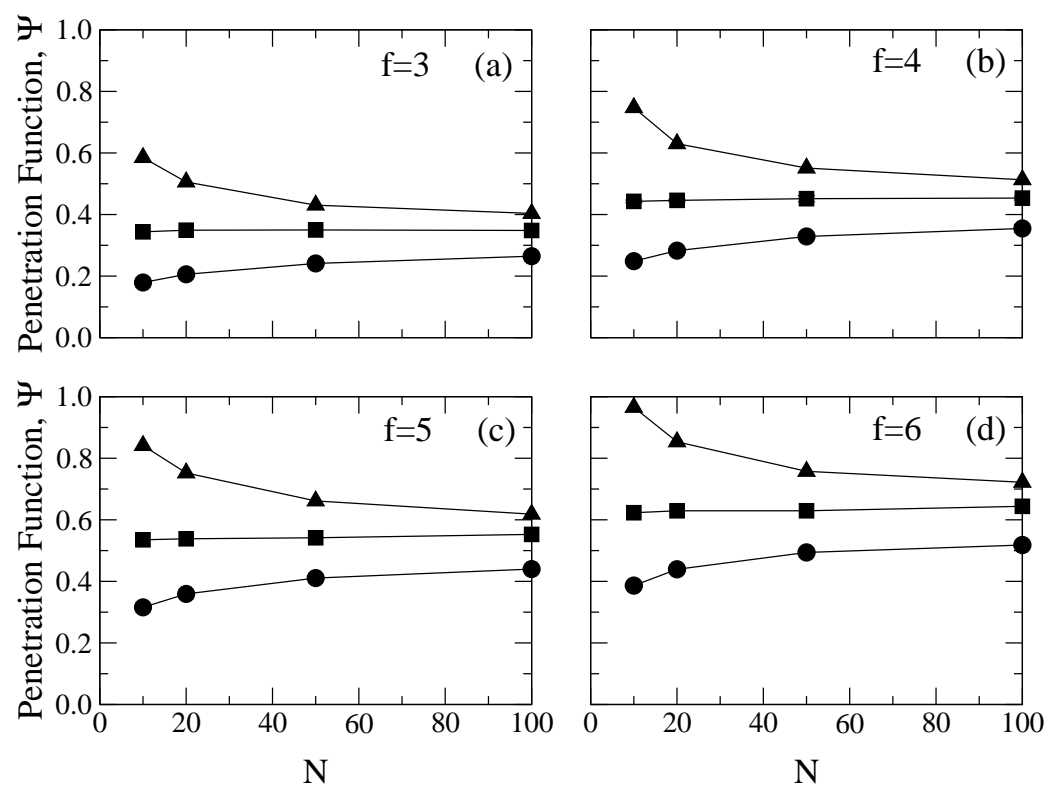

Figure 3. Variation of the penetration function with the degree of polymerization $N$ for (a) $f=3$, (b) $f=4$, (c) $f=5$, and (d) $f=6$ arm stars: (i) $\sigma / l=0.3$ (circles), (ii) $\sigma / l=0.4472$ (squares), and (iii) $\sigma / l=1.0$ (triangles).

value of $\Psi$, the less penetrable a molecule is. For a simple hard sphere, $\Psi \approx 1.6$ [45], and for a linear chain in the infinite molecular weight limit, $\Psi \approx 0.25$ [137-141]. Due to its importance, there have been many experimental $[13,142-146]$ and computer simulation $[45,55,118]$ studies of the penetration function.

As mentioned previously, there are two separate good solvent regions. Each have the same infinite molecular weight limit; however, they differ in their direction of approach to the infinite molecular weight limit. To illustrate this point, in figure 3 we plot the variation of the penetration function $\Psi$ with the number of spheres per $\operatorname{arm} N$ for three-, four-, five-, and six-arm star polymers with various values of $\sigma / l$. For star polymers with $\sigma / l<0.4472$, the penetration gradually increases with molecular weight; for $\sigma / l>0.4472$, the penetration function gradually decreases with molecular weight. Regardless of the value of $\sigma / l$, the penetration function approaches the same asymptotic limit as the molecular weight becomes infinitely large. The closer the value of $\sigma / l$ is to 0.4472 , the more rapidly the penetration function approaches its asymptotic value. This type of behaviour is also exhibited by other properties of star polymers and can be used to obtain accurate bounds for infinite molecular weight properties.

For the hard-sphere star polymer model, the "critical" value of $\sigma / l$ is independent of the number of arms, even for large number of arms. To demonstrate this, we plot the variation of $\Psi$ with $N$ for 18-arm star polymers in figure 4 . For fairly short arm lengths, the penetration function increases for values of $\sigma / l$. However, for large arm lengths (i.e., large enough to consider the molecule a "polymer"), we see the same behaviour that we described above, with the same critical value of $\sigma / l=0.4472$. Precisely at this critical value of $\sigma / l, \Psi$ remains roughly constant, nearly equal to its 


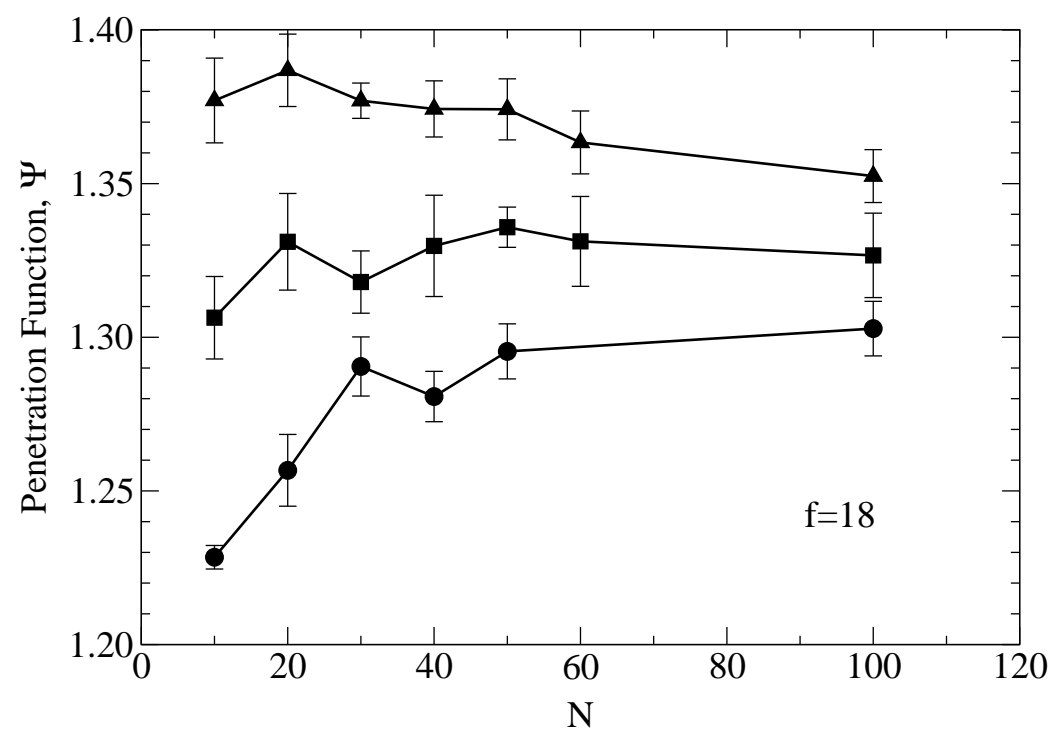

Figure 4. Variation of the penetration function with the degree of polymerization $N$ for $f=18$ arm stars: (i) $\sigma / l=0.4$ (circles), (ii) $\sigma / l=0.4472$ (squares), and (iii) $\sigma / l=0.5$ (triangles).

asymptotic value $\Psi^{*}$ for almost all molecular weights. The condition $\sigma / l=0.4472$, which is identical to the value for linear chains [116], corresponds to the case when the renormalized parameter $\bar{u}=1$, or equivalently $N^{*}=0$ [118], and the system at any $N \gg 1$ exhibits pure Kuhnian scaling behaviour $(\bar{N} \rightarrow \infty)$.

The value of $\sigma / l$ which corresponds to $\bar{u}=1$ (i.e., $\sigma / l=0.4472$ ) is independent of the number of arms $f$ on the star polymer; however, the asymptotic limiting value $\Psi^{*}(f)$ of the penetration function is dependent on $f$. An explanation for the appearance of this type of behaviour has been offered by $\mathrm{Li}$ and coworkers [147] using a Wilson-type renormalization-group argument. Comparison of the calculated with different crossover models values for $\Psi^{*}(f)$ with simulation data for $f \leqslant 41$ is given in figure 5 . The solid curve in figure 5 represents the values calculated with the crossover function obtained by Lue and Kiselev [118], and the dashed curve corresponds to the values calculated with the Douglas-Freed model [136]. As one can see, the Douglas-Freed crossover model even qualitatively is unable to reproduce the simulation data for $f \geqslant 6$, while the crossover function by [118] is in a good agreement with MC simulations and at $f \rightarrow \infty$ yields $\Psi^{*}(\infty)=2.39$, which is close to the value $\Psi^{*}(\infty)=2.13$ obtained by Ohno and co-workers [45]. A summary of $\Psi^{*}(f)$ obtained from previous experimental, simulation, and theoretical studies is given in table 1 of [55]

This same qualitative behaviour has been observed in other models for linear $[116,117,148-151]$ and star polymers $[47,55]$. However, the feature that the critical value of the monomer-monomer interaction (in this case the hard-sphere diameter) is independent of $f$ does not occur in general. In fact, for some polymer models, linear and star polymers can exhibit opposite directions of approach to $\Psi^{*}(f)$. That is, for the same monomer type and solution conditions, linear polymers approach 


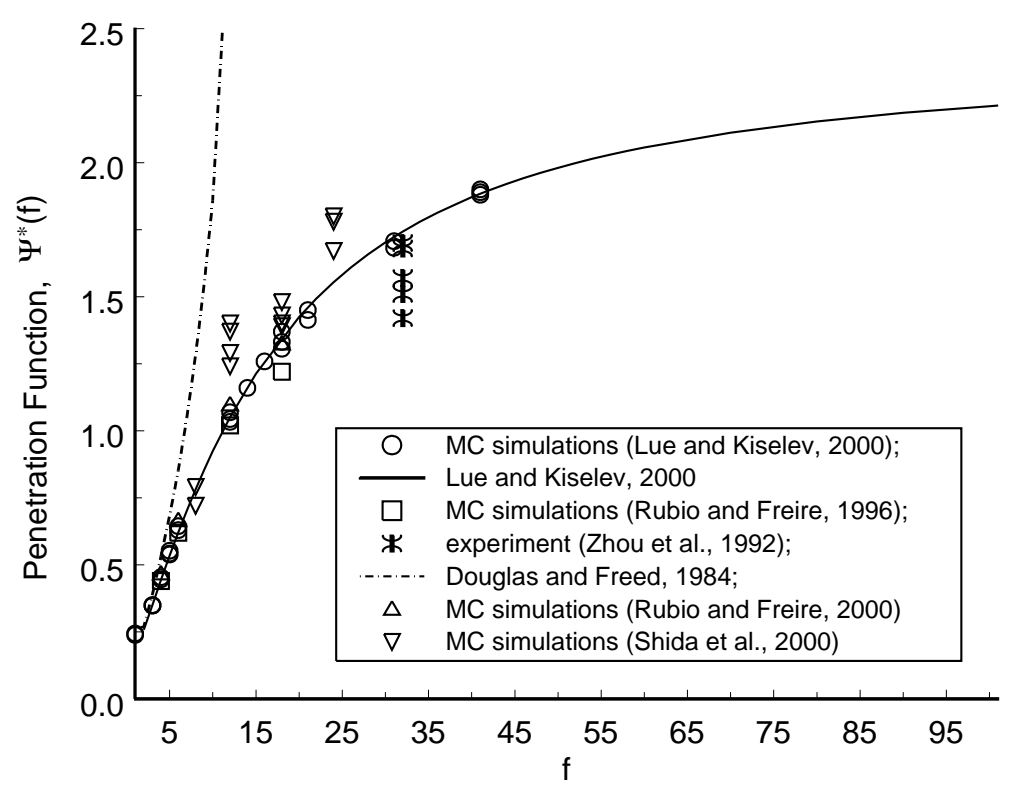

Figure 5. Variation of the infinite molecular weight limit of the penetration function $\Psi^{*}(f)$ with number of arms $f$ : (i) calculated values from [118] and [136] (lines), (ii) simulation data from $[47,55,56]$ (empty symbols), (iii) experimental data from [154] (antz).

$\Psi^{*}$ from below, with increasing molecular weight, while star polymers approach $\Psi^{*}$ from above (for an example, see $[47,55]$ ). This may be due to the vicinity of the theta temperature to the temperature at which the effective two-body interaction parameter $v_{\mathrm{B}}$ in the effective Hamiltonian of the system is nearly equal to zero, or the same renormalized parameter $\bar{u}=v_{\mathrm{B}} L^{4-d}=0$ [118]. In addition, many theoretical $[10,13,32]$, simulation $[67,152]$ and experimental studies $[15,67,69,153]$ have shown that for many model polymers, there is a depression of the theta temperature due to branching. For the hard-sphere star polymer model, $\theta$ conditions are not realized.

\subsection{Interaction between two star polymers}

Recently, there has been interest in studying the interaction between two isolated star polymers. The potential of mean force $w(r)$ is defined as the difference in the free energy when the center of mass of two molecules are separated by a distance $r$ and that when they are infinitely far apart. Based on the Daoud and Cotton model [127], a theoretical form for interaction between a pair of star polymers was proposed by Löwen and coworkers $[2,66,155]$. This effective pair potential was then used to predict the behaviour of bulk solutions of star polymers $[59,155]$ and the regions where crystalline phases formed were found.

The potential of mean force between two star polymers at infinite dilution has also been studied by several researchers using computer simulation methods $[56,67$, 68]. In figure 6 , we plot the potential of mean force between two isolated 6-arm star polymers, as obtained from Monte Carlo simulations.

The potential of mean force also approaches a "universal" form in the infinite 


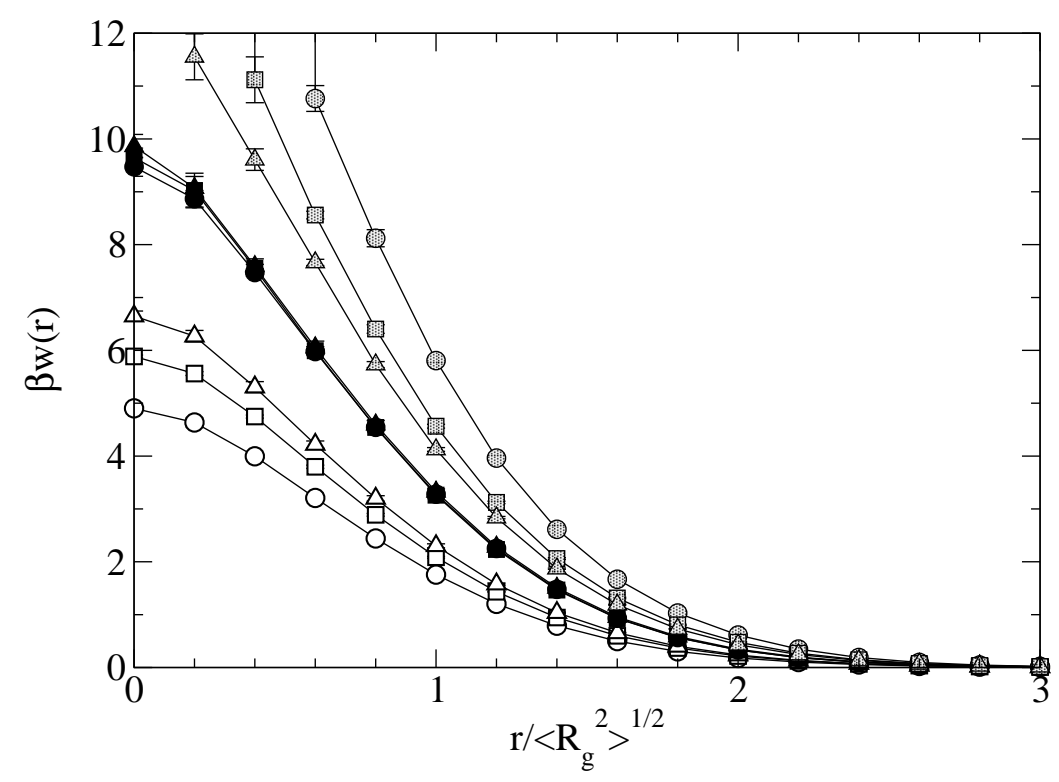

Figure 6. Variation of the potential of mean force with molecular weight for six-arm star polymers: (i) $N=20$ (circles), (ii) $N=50$ (squares), and (iii) $N=100$ (triangles). The open symbols are for $\sigma / l=0.3$, the filled symbols are for $\sigma / l=0.4472$, and the shaded symbols are for $\sigma / l=1.0$.

molecular weight limit. As was the case for the penetration function, there are two directions of approach towards this limiting form. For star polymers with $\sigma / l<$ 0.4472 (see open symbols), this limit is approached from below, while for polymers with $\sigma / l>0.4472$, this limit is approached from above. For polymers with $\sigma / l=$ 0.4472 , we see that the infinitely molecular weight limit is attained very rapidly.

As the number of arms in a star polymer increases, we expect the potential of mean force to increase rapidly at very short distances $r$, due to the fact that the cores of the polymers become more congested. In figure 7 , we plot the Mayer $f$-function for star polymers with varying numbers of arms. The Mayer $f$-function between two molecules is defined as

$$
f(r)=\exp [-\beta w(r)]-1,
$$

where $\beta=1 /\left(k_{\mathrm{B}} T\right)$. The solid line is the Mayer $f$-function between two hard spheres, each of radius $R$, which is given by

$$
f(r)=\left\{\begin{aligned}
-1 & \text { for } r<2 R=2(5 / 3)^{1 / 2} R_{\mathrm{g}} \\
0 & \text { otherwise }
\end{aligned}\right.
$$

As the number of arms in the star polymer increases, we see that the Mayer $f$ function (or, equivalently, the potential of mean force) approaches that of a hard sphere. However, the surface of the star polymer is not sharp, but, instead, is rather diffuse. 


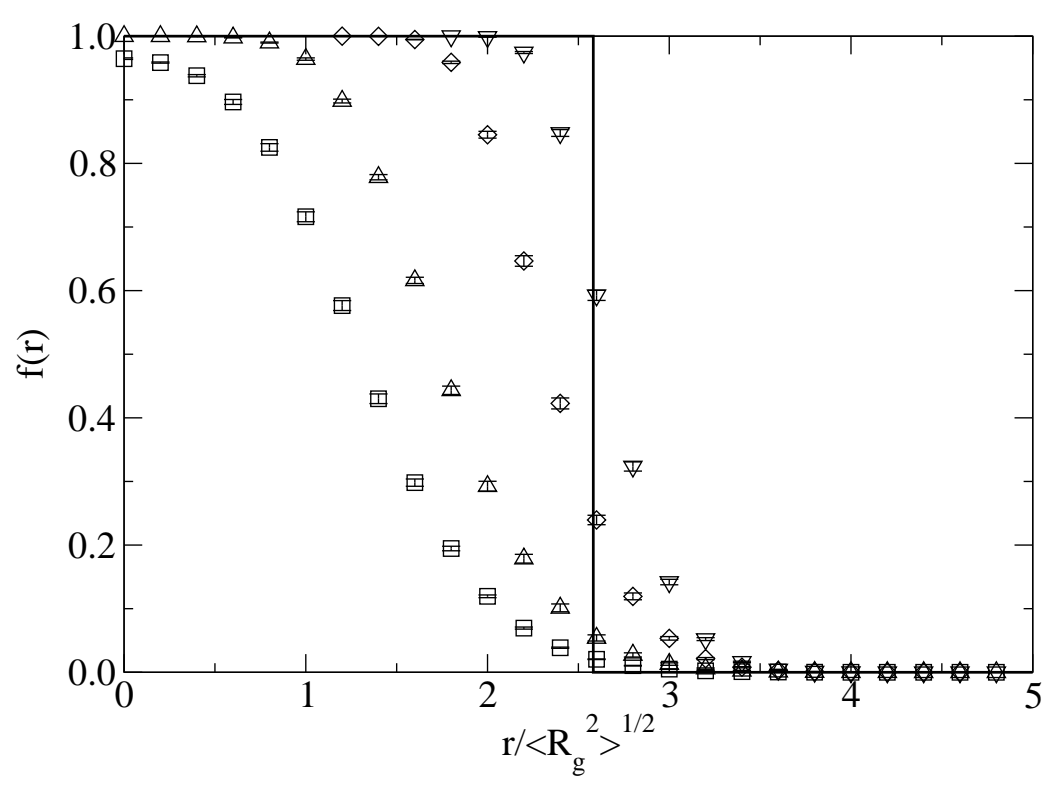

Figure 7. Infinite molecular weight limit of the Mayer $f$-function for star polymers with varying number of arms. The symbols are from Monte Carlo simulations for: (i) $f=1,2$ (circles), (ii) $f=3$ (squares), (iii) $f=6$ (triangles-up), (iv) $f=18$ (diamonds), and (v) $f=41$ (triangles-down).

\subsection{Crossover theory}

The Edwards Hamiltonian provides a coarse-grained description of a polymer chain with excluded-volume interactions $[156,157]$. For star polymers, the Edwards Hamiltonian generalizes to [129]

$$
H[R]=\frac{1}{2} \sum_{\alpha=1}^{f} \int_{0}^{S_{\mathrm{B}}} \mathrm{d} t_{\alpha}\left(\frac{\partial R\left(t_{\alpha}\right)}{\partial t_{\alpha}}\right)^{2}+\frac{v_{\mathrm{B}}}{2} \sum_{\alpha, \gamma=1}^{f} \int_{0}^{S_{\mathrm{B}}} \mathrm{d} t_{\alpha} \int_{0}^{S_{\mathrm{B}}} \mathrm{d} t_{\gamma}^{\prime} \delta\left(R\left(t_{\alpha}\right)-R\left(t_{\gamma}^{\prime}\right)\right),
$$

where $f$ is the number of arms on the star polymer, $S_{\mathrm{B}}$ is related to the molecular weight of each arm of the star polymer, $v_{\mathrm{B}}=b_{\mathrm{B}} d^{2} / l^{4}$ is an effective segment-segment interaction parameter which measures the strength of the excluded-volume interaction, and $R\left(t_{\alpha}\right)$ is the position of "segment" $t_{\alpha}$ on arm $\alpha$ of the star polymer. The first term enforces the connectivity of the polymer, and the second term accounts for excluded volume interactions between "segments" of the polymer. Due to the coarse-grained nature of the Edwards Hamiltonian, it is limited to polymers with many statistical segments [158].

When $v_{\mathrm{B}} \neq 0$, the model is not exactly solvable, and approximate methods, such as renormalized perturbation theory, need to be used (see [159] and [160] for details). In renormalized perturbation theory, a general property $Q$ is given by

$$
Z_{Q}^{-1}(u) Q(u, S ; L)=\lim _{a \rightarrow 0} Q_{\mathrm{B}}\left(v_{\mathrm{B}}, S_{\mathrm{B}} ; a\right),
$$

where $Q_{\mathrm{B}}$ is the value of the property obtained from a bare perturbation expansion, $a$ is a cutoff length for the model, and $L$ is the length scale at which the property is 
measured. The function $Z_{Q}(u)$ and the renormalized model parameters $u=v L^{\epsilon}$ and $S=N l^{2} / d$ (where $\epsilon=4-d$ and $v$ is a renormalized segment-segment interaction parameter) of the Edwards Hamiltonian are chosen to absorb the divergences of the theory as $a \rightarrow 0$. The values of the renormalized parameters $u$ and $S$ depend on $L$, but despite this, the measurable properties of the system $Q$ should be independent of the length scale at which they are measured. This independence leads to the renormalization group equation, which relates the renormalized parameters of the model at length scale $L_{R}\left(u_{R}\right.$ and $\left.S_{R}\right)$ to the parameters at length scale $L(u$ and $S)$. To the second order in $\epsilon$, this is given by $[116,118]$

$$
\begin{aligned}
1-Y & =\bar{u}(1-\bar{u})^{-\epsilon / \omega}\left(\frac{L_{R}^{2}}{L^{2}}\right)^{\epsilon / 2} Y^{\epsilon / \omega}, \\
\frac{S_{R}}{S} & =(1-\bar{u})^{(2-1 / \nu) / \omega} e^{-\kappa(1-\bar{u})} Y^{-(2-1 / \nu) / \omega} \mathrm{e}^{\kappa Y},
\end{aligned}
$$

where $u^{*} \approx 0.1771$ [131], $Y=1-u_{R}, \bar{u}=u / u^{*}, \kappa=11 u^{*} / 16$, and $\nu$ and $\omega$ are universal exponents. The best estimates of these exponents are $\nu=0.588$ and $\omega=0.790$ [131].

The results should be independent of the match point, $L_{R}$. However, in practice, since a truncated perturbation expansion is typically used, the results do depend on the precise choice of the match point. In general, the match point is chosen to optimize the convergence of the perturbation expansion. By choosing a match point of $L_{R}^{2}=f S_{R}$, the equation for the crossover function becomes [116,118]

$$
(1-Y)^{2 / \epsilon}=\bar{N} Y^{1 / \Delta} \mathrm{e}^{\kappa Y},
$$

where we use the relations $\Delta=\omega \nu, \bar{N}=f N / N^{*}$, and $N^{*}$ is given by

$$
N^{*}=(\bar{u} \Lambda)^{-2}|1-\bar{u}|^{1 / \Delta} \mathrm{e}^{\kappa(1-\bar{u})},
$$

where $\Lambda^{-2}=L^{2} d / l^{2}$ is a system-dependent parameter. The parameter $\bar{u}$ is related to the second virial coefficient $b$ of the monomer-monomer interaction through the following equation [117]

$$
\bar{u}=\frac{\kappa_{1}}{\Lambda}\left(\frac{2 \pi}{3}\right)^{-3 / 2} \frac{b}{l^{3}}
$$

where $\kappa_{1}$ is a constant which will be determined later. For hard spheres of diameter $\sigma, b=2 \pi \sigma^{3} / 3$.

To the second order in $\epsilon$, the penetration function of a star polymer with $f$ arms is given by [129]

$$
\Psi=\frac{g^{d / 2}}{8} \bar{u}_{R}\left[a_{0}+\frac{\bar{u}_{R}}{8}\left(a_{1}-b_{1}\right)+\cdots\right]
$$

where

$$
\begin{aligned}
g & =\frac{f^{2}}{3 f-2}, \\
a_{0} & =53 / 32,
\end{aligned}
$$




$$
\begin{aligned}
& a_{1}=\frac{1}{2} \ln 2+\frac{7}{48}+\frac{13}{8} \frac{(f-1)(f-2)}{3 f-2} \\
& b_{1}=\frac{1}{4} \frac{(f-1)(15 f-22)}{3 f-2} \ln 2+\left(\frac{9}{8} \ln 3-\frac{7}{4} \ln 2\right)(f-1)(f-2)-\frac{1}{2} \ln f .
\end{aligned}
$$

As observed by previous researchers $[129,136]$, this expression, which is exact to the second-order in $\epsilon$, is not very accurate at low values of $f$ and provides unphysical negative values for the penetration function for large values of $f$. An explicit expression for the penetration function, which has a different form from equation (22), has been obtained by Douglas and Freed [136]. However, as we have shown above (see figure 5), this expression also fails to accurately reproduce the simulation data for the penetration function with $f \geqslant 6$, which restricts its application to real physical systems.

A phenomenological procedure dealing with crossover behaviour of star polymers, based on a crossover approach developed earlier for simple fluids near the second-order phase transitions [100], was developed by Lue and Kiselev [118]. In this approach, the form of the crossover expression for the penetration function which is valid for any number of arms $f$, is obtained from the $\epsilon$-expansion, but the values of the universal coefficients are fixed from some well established matching conditions. Keeping the $\mathrm{RG}$ expression for the penetration function exact to the second-order in $\epsilon$, Lue and Kiselev [118] obtained

$$
\Psi=\frac{g^{d / 2}}{8}(1-Y)\left[\frac{a_{0}+a_{1}(1-Y)+a_{2}(1-Y)^{2}}{1+b_{1}(1-Y)+b_{2}(1-Y)^{2}}\right],
$$

where the parameters $g, a_{0}, a_{1}$, and $b_{1}$ are defined by equation (26), and $a_{2}$ and $b_{2}$ are analytic functions of $f$

$$
\begin{aligned}
& a_{2}=a_{2}^{(0)}+a_{2}^{(1)}(f-1)(f-2), \\
& b_{2}=\left(b_{2}^{(0)}+b_{2}^{(1)} g^{d / 2}+b_{2}^{(2)} \ln f\right)(f-1)(f-2),
\end{aligned}
$$

where parameters $a_{2}^{(0)}, a_{2}^{(1)}, b_{2}^{(0)}, b_{2}^{(1)}$, and $b_{2}^{(2)}$ are independent of the details of the monomer-monomer interactions in the star polymer. For the coefficient $a_{2}^{(0)}=$ -0.087, Lue and Kiselev [118] adopted the same value as for linear polymer [117], which corresponds to $\Psi^{*}(f=1,2)=0.2577$, while the parameters

$$
a_{2}^{(1)}=2.643, \quad b_{2}^{(0)}=0.662, \quad b_{2}^{(1)}=0.138, \quad b_{2}^{(2)}=0.357
$$

were found from a fit of equation (27) to the $\Psi^{*}$-simulation data for $2 \leqslant f \leqslant 41$. Thus, the crossover model as given by equations (27)-(30) is actually a phenomenologically "repaired" crossover function, exact to the second-order in $\epsilon$.

The crossover expression for the penetration function for star polymers in this model is completely determined by equations (27)-(29), where the crossover function $Y$ is given by equation (19) with $\epsilon=1$ (for 3-dimensional systems), and the parameter $\bar{u}$ is calculated with equation (21). For the cases $f=1$ and 2 , equation (27) 


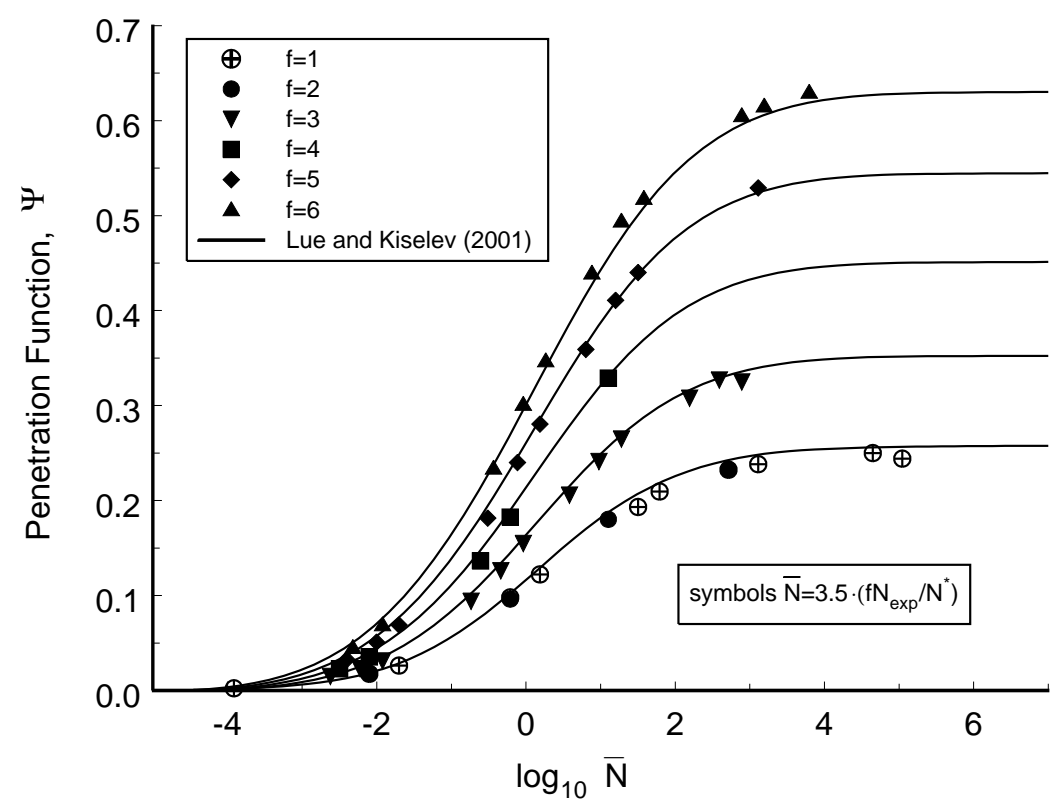

Figure 8. Crossover of the penetration function $\Psi(\bar{N}, f)$ with the rescaled degree of polymerization $\bar{N}=f N / N^{*}$ : (i) simulation data from [118] with renormalized values $\bar{N}=3.5\left(f N_{\exp } / N^{*}\right)$ (symbols), (ii) calculated values with equation (27) (lines).

reduces to the corresponding expression for the linear chains [see equation (26) in [117]]. In the limit of infinitely long chains (i.e., $\bar{N} \rightarrow \infty$ ), the penetration function reaches an asymptotic value $\Psi^{*}(f)$, as discussed above (see figure 5 ). Noting that for hard-sphere polymers $\bar{u}=1$ when $\sigma / l=0.4472$, independently of the number of arms on the star polymer, and choosing $\Lambda^{-2}=10$, we find that $\kappa_{1}=5.11654$ in equation (21), as for linear chains [117]. For the hard-sphere polymers with $\sigma / l \leqslant 0.4472$, equation (21) is transformed to [116]

$$
\bar{u}=11.18\left(\frac{\sigma}{l}\right)^{3} .
$$

The Edwards Hamiltonian is valid only for the situation where $\bar{u} \leqslant 1$ and $\Psi(f)<$ $\Psi^{*}(f)$, which is the case for fully flexible polymers. Therefore, the crossover model presented here is valid only for hard-sphere polymers with $\sigma / l \leqslant 0.4472$. The case $\bar{u}>1$ describes the crossover behaviour of stiff or semiflexible polymers. We do not consider this situation.

In figure 8 , we compare simulation data for $0.1 \leqslant \sigma / l<0.4472$ to the values of the penetration function calculated with equations (27) and (30). We need to note, that the rescaling factor of the parameter $\bar{N}=3.5\left(f N_{\exp } / N^{*}\right)$ for the MC simulation data for penetration function in figure 8 is not the same as for the centerto-end distance in figure 2. As it was pointed out by Lue and Kiselev [118], this corresponds to choosing a match point of $L_{R}^{2}=3.5 f S_{R}$ in equation (17), rather than $L_{R}^{2}=f S_{R}$ adopted for linear polymer [117]. After this rescaling, excellent agreement between the simulation data and the calculated values of the penetration 


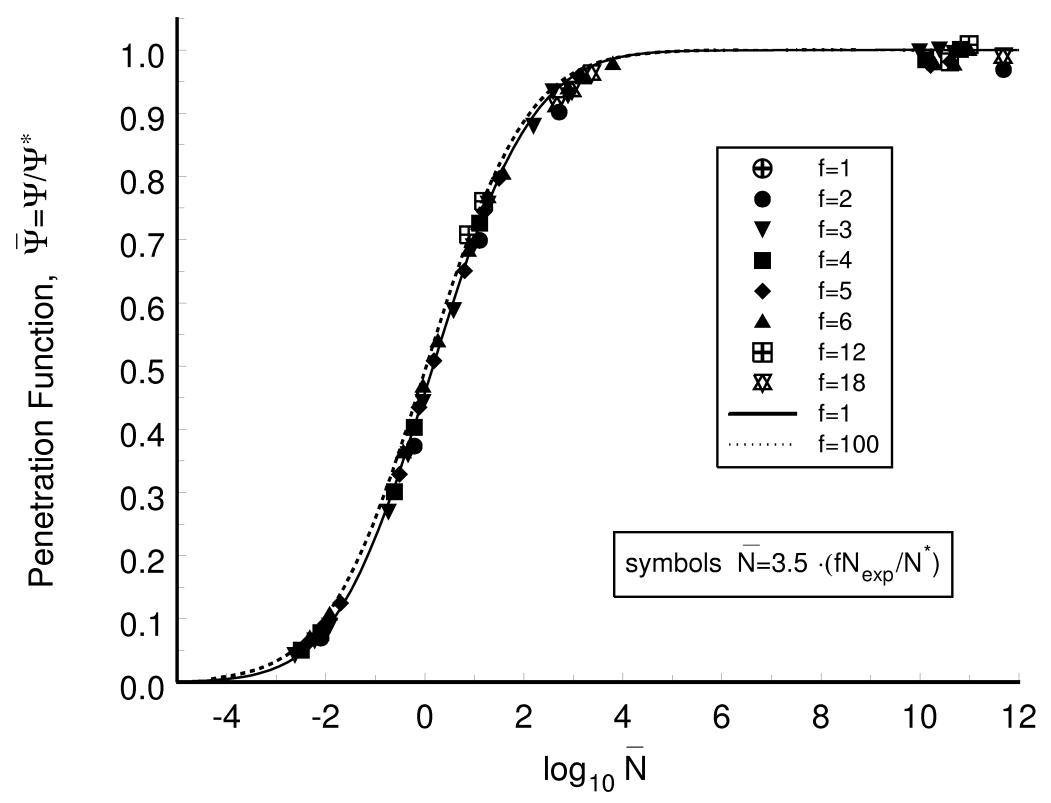

Figure 9. Variation of the rescaled penetration function $\bar{\Psi}(\bar{N}, f)=$ $\Psi(\bar{N}, f) / \Psi^{*}(f)$ with the rescaled degree of polymerization $\bar{N}=f N / N^{*}$ : (i) simulation data from [118] with renormalized values $\bar{N}=3.5\left(f N_{\exp } / N^{*}\right)$ (symbols),

(ii) calculated values (line).

function is obtained in the entire range of $\bar{N}$. In figure 9 we show the rescaled penetration function $\bar{\Psi}=\Psi(N, f) / \Psi^{*}(f)$ as a function of the rescaled degree of polymerization $\bar{N}=f N / N^{*}$. The dotted curve in figure 9 represents the values of the rescaled penetration function $\bar{\Psi}$ calculated for star polymers with $f=100$. As one can see, the two curves, calculated with $f=1$ and $f=100$, lie very close to each other and, within accuracy of the simulation data, the rescaled penetration function $\bar{\Psi}$ can be considered a universal function of the parameter $\bar{N}$ only. As we will show in the next section, this conclusion is extremely important for the prediction of the thermodynamic properties of star polymers in dilute/semidilute regimes.

\section{Dilute and semidilute regimes}

In the dilute and semidilute regimes, the connectivity of the polymers induces long-range correlations between the monomer segments. The details of the monomermonomer interactions do not play a major role; thus, a coarse-grained description of the polymers, such as the Edwards Hamiltonian [156,157], can be used. For a system of star polymers, the grand partition function $\Xi$ is given by [129]

$$
\begin{aligned}
\Xi[\gamma]=\sum_{N_{\mathrm{p}}=0}^{\infty} & \frac{1}{N_{\mathrm{p}} !} \int D R_{1}^{1}(\cdot) D R_{1}^{2}(\cdot) \cdots D R_{f}^{N_{\mathrm{p}}}(\cdot) \\
& \times \exp \left\{\sum_{k=1}^{N_{\mathrm{p}}} \sum_{\alpha=1}^{f} \int_{0}^{S_{\mathrm{B}}} \mathrm{d} t_{\alpha} \gamma\left(R_{\alpha}^{k}\left(t_{\alpha}\right)\right)-\frac{1}{2} \sum_{k=1}^{N_{\mathrm{p}}} \sum_{\alpha=1}^{f} \int_{0}^{S_{\mathrm{B}}} \mathrm{d} t_{\alpha}\left(\frac{\partial R_{\alpha}^{k}\left(t_{\alpha}\right)}{\partial t_{\alpha}}\right)^{2}\right.
\end{aligned}
$$




$$
\left.-\frac{v_{\mathrm{B}}}{2} \sum_{k, l=1}^{N_{\mathrm{p}}} \sum_{\alpha, \tau=1}^{f} \int_{0}^{S_{\mathrm{B}}} \mathrm{d} t_{\alpha} \int_{0}^{S_{\mathrm{B}}} \mathrm{d} t_{\tau} \delta\left(R_{\alpha}^{k}\left(t_{\alpha}\right)-R_{\tau}^{l}\left(t_{\tau}\right)\right)\right\},
$$

where $\gamma$ is an external field that couples to the monomers of the star polymer, $N_{\mathrm{p}}$ is the number of star polymers in the system, and $R_{\alpha}^{k}\left(t_{\alpha}\right)$ is the position of "segment" $t_{\alpha}$ on arm $\alpha$ of star polymer $k$. The first term in the argument of the exponential accounts for the interaction of the polymer segments with the external field $\gamma$, the second term enforces the connectivity of the polymer, and the third term accounts for excluded volume interactions between "segments" of the polymer. Due to the coarse-grained nature of the Edwards Hamiltonian, this approach is limited to polymers with many statistical segments [158].

Summing all diagrams with at most one loop yields the following approximation for the Helmholtz free energy $F$ of the system [157,161]:

$$
\frac{\beta F}{V}=c_{\mathrm{p}}\left[\ln \frac{c_{\mathrm{p}}}{Q_{0}}-1\right]+\frac{1}{2} v_{\mathrm{B}} f^{2} S_{\mathrm{B}}^{2} c_{\mathrm{p}}^{2}+\frac{1}{2} \int_{q} \ln \left[1+v_{\mathrm{B}} f^{2} S_{\mathrm{B}}^{2} c_{\mathrm{p}} g_{0}\left(\frac{q^{2} f S_{\mathrm{B}}}{2}\right)\right]+\cdots,
$$

where $V$ is the volume of the system, $Q_{0}$ is the partition function of an isolated, noninteracting star polymer, $\int_{q} \rightarrow \int \mathrm{d}^{d} q /(2 \pi)^{d}$, and $g_{0}$ is the Debye scattering function, which for star polymers is given by [162]

$$
g_{0}(x)=\frac{2}{x^{2}}\left\{x+f\left(\mathrm{e}^{-x / f}-1\right)\left[1+\frac{f-1}{2}\left(\mathrm{e}^{-x / f}-1\right)\right]\right\} .
$$

This expression can be rewritten in a more useful form if we replace the "bare" parameters of the Edwards Hamiltonian (e.g., $S_{\mathrm{B}}, v_{\mathrm{B}}$, etc.) with experimentally measurable quantities (e.g., the second virial coefficient $B_{2}$, penetration function $\Psi$, etc.). Performing this replacement consistently to one-loop order yields $[163,164]$

$$
\begin{aligned}
& \frac{\beta F}{V}=c_{\mathrm{p}}\left[\ln \frac{c_{\mathrm{p}}}{Q}-1\right] \\
& +c_{\mathrm{p}} X \exp \left[\frac{(4 \pi)^{d / 2} \Psi}{4 g^{d / 2} X^{2}} \int_{q}\left\{\ln \left[1+2 X g_{0}\left(q^{2}\right)\right]-2 X g_{0}\left(q^{2}\right)+2 X^{2} g_{0}^{2}\left(q^{2}\right)\right\}+\cdots\right],
\end{aligned}
$$

where $X=B_{2} c_{\mathrm{p}}$, and $g=f^{2} /(3 f-2)$.

To obtain an analytical expression for the free energy, we approximate the Debye scattering function as [161]

$$
g_{0}(x) \approx \frac{1}{1+x / \mu}+\cdots
$$

where $\mu$ is a parameter (dependent on the number of arms $f$ on the star polymer) which will be determined later. The integral in equation (35) can then be evaluated analytically to yield a closed form for the free energy through

$$
\frac{\beta F}{V}=c_{\mathrm{p}}\left[\ln \frac{c_{\mathrm{p}}}{Q}-1\right]+c_{\mathrm{p}} X \exp \left[-\frac{\Psi}{4 K} A(X)\right],
$$


where $K=2(g / \mu)^{d / 2}$, and $A(x)=x^{-2}\left[2 x+6 x^{2}-(1+2 x)^{2} \ln (1+2 x)\right]$. This free energy leads to a compressibility factor $Z=\beta \Pi / c_{\mathrm{p}}$ of the form

$$
Z=1+X\left[1+\frac{\Psi}{2 K} B(X)\right] \exp \left[-\frac{\Psi}{4 K} A(X)\right]
$$

where $B(x)=x^{-2}\left[2 x+2 x^{2}-(1+2 x) \ln (1+2 x)\right]$.

In the semidilute regime $(X \gg 1)$ for extremely-large-molecular-weight polymers, the compressibility factor given in equation (38) scales with the polymer concentration as

$$
Z \propto c_{\mathrm{p}}^{1+\Psi^{*}(f) / K}
$$

This should be compared with the results from scaling arguments [120,121], commonly referred to as des Cloizeaux's law,

$$
Z \propto c_{\mathrm{p}}^{1 /(d \nu-1)}
$$

which should be independent of the polymer architecture. In order to satisfy this scaling relation, valid in the infinite-molecular-weight limit, we must have

$$
\frac{\Psi^{*}(f)}{K}=\frac{\alpha}{1-\alpha}
$$

where $\alpha=2-d \nu \approx 0.236$.

Therefore, we find

$$
\begin{aligned}
\frac{\beta F}{V} & =c_{\mathrm{p}}\left[\ln \frac{c_{\mathrm{p}}}{Q}-1\right]+c_{\mathrm{p}} X \exp \left[-\frac{\kappa \bar{\Psi}}{4} A(X)\right], \\
Z & =1+X\left[1+\frac{\kappa \bar{\Psi}}{2} B(X)\right] \exp \left[-\frac{\kappa \bar{\Psi}}{4} A(X)\right],
\end{aligned}
$$

where $\bar{\Psi}$ is a rescaled penetration function introduced above, and $\kappa=\alpha /(1-\alpha) \approx$ 0.3089 is a universal constant. Written in this form, the polymer architecture does not enter explicitly into the thermodynamic properties of the system. As demonstrated previously, the rescaled penetration function $\bar{\Psi}$ with a high accuracy is a universal function of the parameter $\bar{N}$; the only distinction between different architectures is the asymptotic limit of the penetration function $\Psi^{*}$. Therefore, equation (43) predicts that the equation of state in the dilute/semidilute regimes for all polymers should approach the same limiting form, regardless of the architecture, as the molecular weight of the polymer becomes infinitely large.

In the previous section, it was shown that there are two types of approach to the infinite molecular weight limit, in a good solvent regime. For stiff polymers, $\bar{\Psi}>1$, and gradually decreases to $\bar{\Psi}=1$ as the molecular weight increases $[117,118,149$, $150,165]$. For fully flexible polymers $\bar{\Psi}<1$, and gradually increases as the molecular weight increases $[117,118,149,150,165]$. Therefore, according to equation (43), for stiff polymers in the dilute/semidilute regime, we expect the compressibility factor to decrease to the infinite-molecular-weight limit as the molecular weight of the 


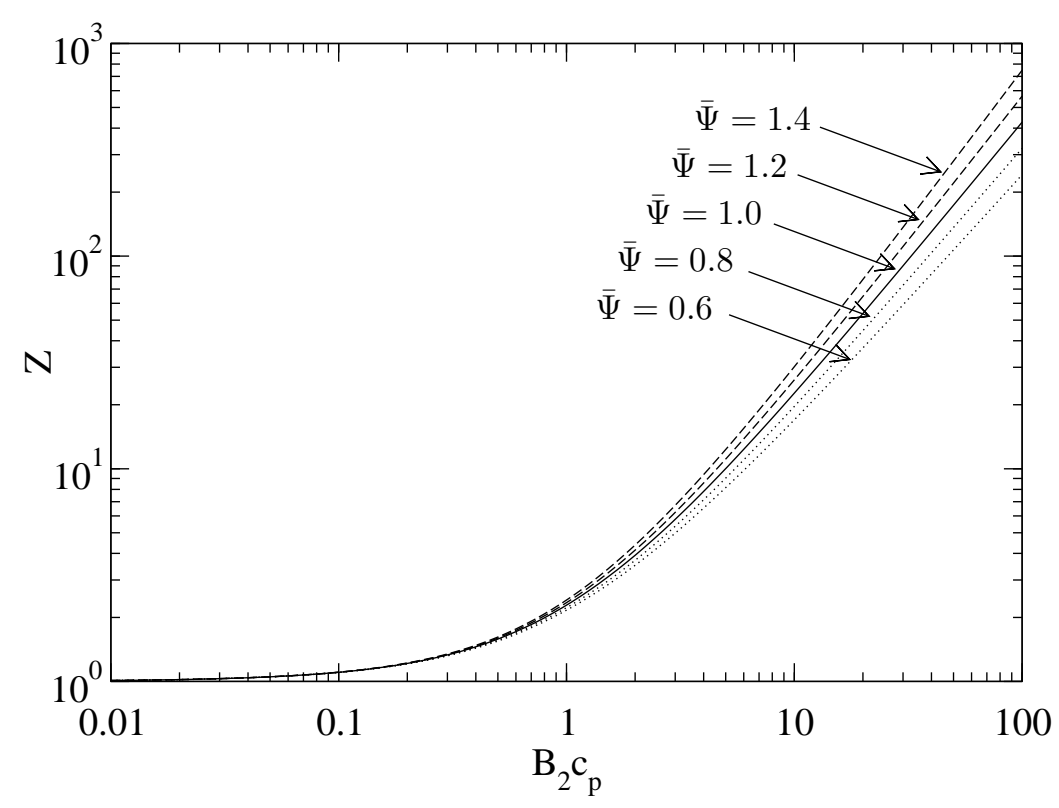

Figure 10. Deviation of the equation of state from the infinite molecular weight limit: (i) $\bar{\Psi}=1$, infinite molecular weight limit (solid line), (ii) $\bar{\Psi}>1$, stiff polymer of finite molecular weight (dashed lines), and (iii) $\bar{\Psi}<1$, flexible polymer of finite molecular weight (dotted lines).

polymer increases, while for flexible polymers, we expect the compressibility factor to increase. This is shown in figure 10, where the dashed lines represent polymer systems with $\bar{\Psi}>1$, the dotted lines represent systems with $\bar{\Psi}<1$, and the solid line is a system with $\bar{\Psi}=1$ (infinite-molecular-weight limit).

In the semidilute regime, where $X \gg 1$,

$$
\begin{aligned}
\frac{\beta \Pi}{c_{\mathrm{p}}} & \sim m X^{\hat{p}}, \\
\frac{\partial \beta \Pi}{\partial c_{\mathrm{p}}} & \sim m^{\prime} X^{1+\hat{p}},
\end{aligned}
$$

where the prefactors $m$ and $m^{\prime}$ and the exponent $\hat{p}$ are given by

$$
\begin{aligned}
m & =(1+\kappa \bar{\Psi}) \exp \left[-\left(\frac{3}{2}-\ln 2\right) \kappa \bar{\Psi}\right] \\
m^{\prime} & =\left[2+3(\kappa \bar{\Psi})+(\kappa \bar{\Psi})^{2}\right] \exp \left[-\left(\frac{3}{2}-\ln 2\right) \kappa \bar{\Psi}\right] \\
\hat{p} & =1+\kappa \bar{\Psi} .
\end{aligned}
$$

In the infinite molecular weight limit, when $\bar{\Psi}=1$, we find $m \approx 1.0202, m^{\prime} \approx 2.3554$, and $\hat{p} \approx 1.3089$. These values are in good agreement with those extracted from experimental studies [162].

The apparent exponent $\hat{p}$ of a large but finite polymer is controlled by the property $\bar{\Psi}$. For $\bar{\Psi}>1$, the apparent exponent will be greater than the infinite molecular 
weight limit, while for $\bar{\Psi}<1$, it will be lower. For most experimental systems, $\bar{\Psi}<1$ only in a narrow region about the theta temperature.

Many experimental studies on star polymers find that the apparent exponent of star polymers deviates from the theoretical value. We propose that this deviation is due to the fact that the experimental systems use polymers with molecular weights that are too small to have reached the infinite molecular weight limit and correspond to the case where $\bar{\Psi} \neq 1$. The rate at which $\bar{\Psi}$ approaches one with increasing molecular weight depends on the details of the system (e.g., the polymer chemistry, solvent, temperature, etc.) $[13,25,62,166]$.

Another reason for the deviation from the expected scaling behaviour is the approach of the concentrated regime. As the concentrated regime is approached, the thermodynamic properties of the polymer system will deviate rapidly from the scaling results. The above arguments apply only to "very long" polymers in the semidilute regime. As the polymers decrease in molecular weight, the width of the semidilute regime decreases. The actual rate at which this occurs depends on the details of the system.

Another type of "universal" is exhibited in this region. The variation of the osmotic pressure of the system with monomer concentration is no longer dependent on the architecture or on molecular weight of the system; however, the form of this function is dependent on the details of the system. In the next section, we discuss an approach for accounting for the details of the monomer-monomer interaction.

\section{Concentrated regime}

\section{1. "Universality" in the concentrated regime}

In figure 11, we plot the variation of the osmotic pressure with the monomer packing fraction for tangent hard-sphere linear and star polymers $(\sigma / l=1)$ with various molecular weights. The symbols are the results of computer simulations. The dotted line represents the pressure of a monomer hard-sphere fluid, as given by the Carnahan-Starling equation of state [167]; the solid line is the pressure of chain molecules in the infinite molecular weight limit, as predicted by thermodynamic perturbation theory (TPT) [168-170]. The pressure of the polymers is lower than that of the monomer hard-sphere fluid at the same packing fraction. This lowering of the pressure is due to the bonds which connect the spheres in the chain fluid. These bonds can be thought as an attractive force between the spheres, which lower the pressure.

In the concentrated regime, the polymer molecules are highly interpenetrated, and the monomers exist in a fairly crowded environment. The connectivity of the monomers is felt only on a local level. One monomer segment knows that it is connected to its immediate neighbours; however, it does not "know" that it is connected to its distant (in terms of bonding along the molecule) neighbour in the same molecule. The interactions with other monomer segments effectively screen the long-range correlations due to the bonding constraints between monomers on 


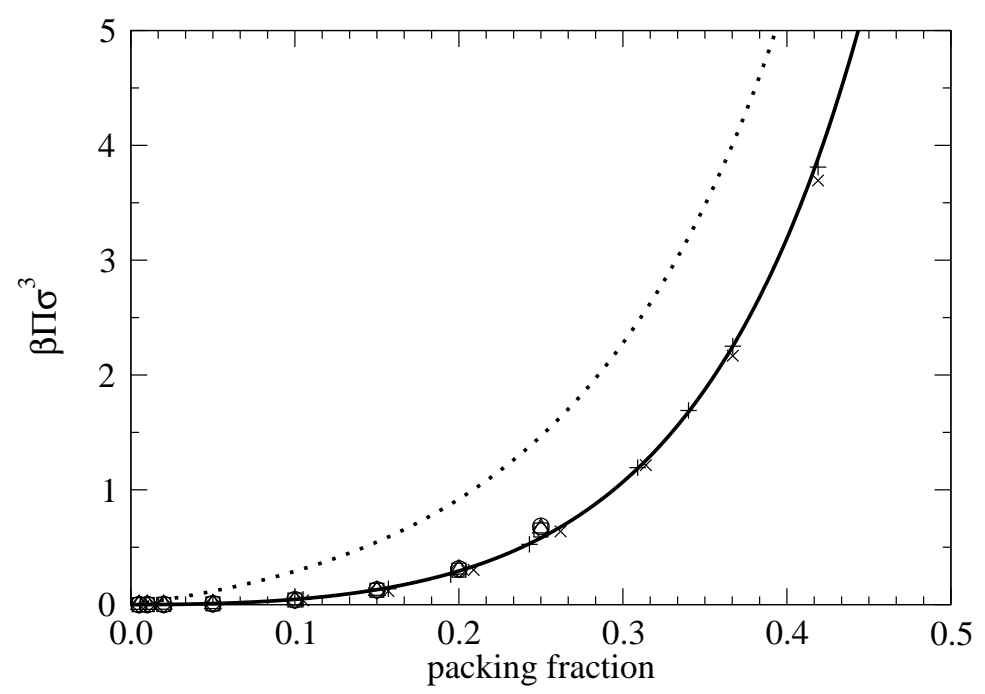

Figure 11. Pressure of tangent-hard-sphere linear and star polymers as a function of monomer packing fraction $y$ : (i) linear chain with $N=51$ (pluses), (ii) linear chain with $N=201$ (crosses), (iii) star polymer with $f=3$ and $N=20$ (circles), (iv) star polymer with $f=4$ and $N=20$ (squares), (v) star polymer with $f=5$ and $N=20$ (triangles), and (vi) star polymer with $f=6$ and $N=20$ (diamonds). The solid line is the prediction of the TPT equation of state for linear chains as $N \rightarrow \infty$. The dotted line is the Carnahan-Starling equation of state for a hard-sphere monomer fluid.

the same molecule. Therefore, the connectivity can be taken into account in an average, or mean-field, manner. Disconnecting the bonds in the system does not significantly alter the structure of the system. That is why the approaches such as the Flory-Huggins [171] model and thermodynamic perturbation theory (TPT) [168170], which account for bonding only on a local level, are successful in this regime. Consequently, the overall architecture of the polymer does not play a significant role in determining the thermodynamics of the system. This can be seen from figure 11, where the results for various architectures appear to lie on the same curve.

On the other hand, the thermodynamic properties of polymers in the concentrated regime are highly dependent on the details of the monomer-monomer interactions. This is in direct contrast to the dilute and semi-dilute regimes, where the details of the monomer are unimportant, although the polymer architecture plays a major role in determining the thermodynamic properties of the solution.

In figure 12, we compare the predictions of the TPT equation of state for dilute/semidilute tangent hard-sphere systems with Monte Carlo simulation data. In the dilute and semidilute regions, the TPT equation of state predicts the pressure of the system, and the results steadily worsen with the decreasing polymer concentration and with the increasing $N$. This is due to the fact that the connectivity of the polymer is accounted for only at a local level, and, consequently, the TPT equation possesses a second virial coefficient $B_{2}$ which scales incorrectly with the degree of polymerization $\left(B_{2} \propto N^{2}\right.$ rather than $\left.B_{2} \propto N^{d \nu}\right)$. As a result, the TPT equation 


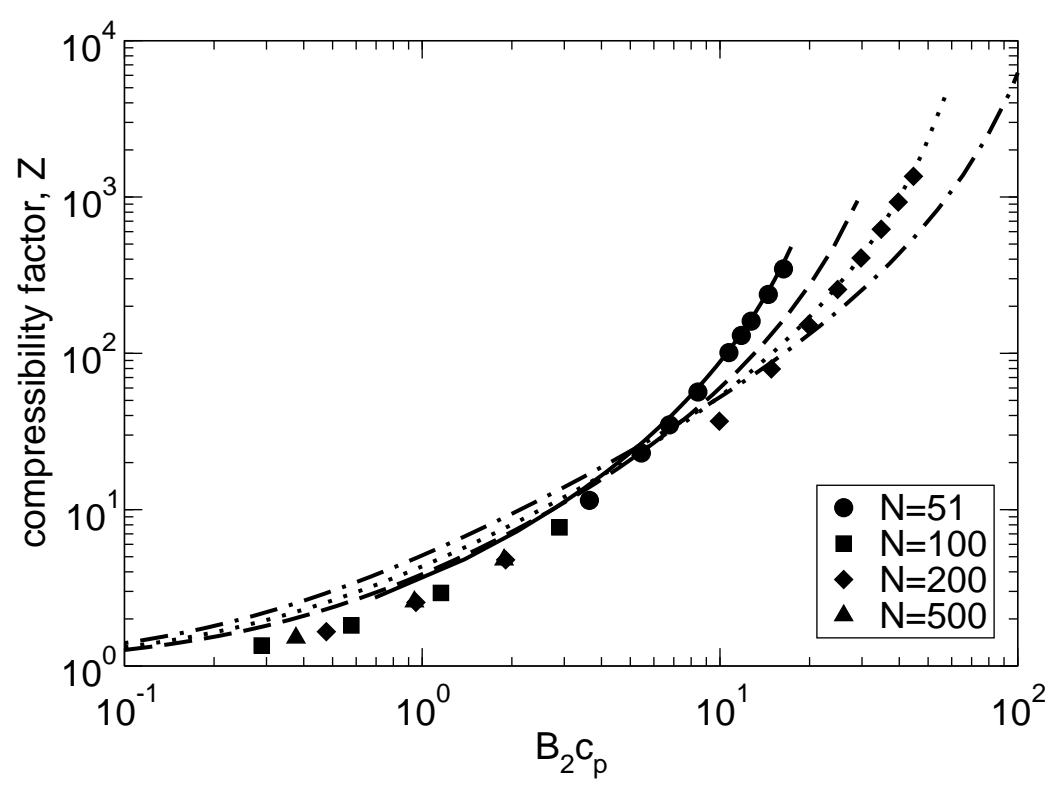

Figure 12. Equation of state of tangent hard-sphere chains in the dilute to concentrated regimes. The symbols are the results of computer simulations for $N=51$ (circles), $N=100$ (squares), $N=200$ (diamonds), and $N=500$ (triangles). The lines are the predictions of the TPT equation of state for: $N=51$ (solid line), $N=100$ (dashed line), $N=200$ (dotted line), and $N=500$ (dashed-dotted line).

of state does not yield a correct universal form for dilute to semidilute solutions of high molecular weight polymers (see equation (43)). This conclusion applies to all equations of state that possess a second virial coefficient that scales with molecular weight as $B_{2} \propto N^{2}$. Thus, these types of equations of state cannot properly describe the behaviour of dilute to semidilute polymer systems.

\subsection{Theoretical considerations}

In the development of free energy of a polymer system in the dilute and semidilute regimes, we employed the Edwards Hamiltonian, which neglects the details of the monomer-monomer interactions. In the concentrated regime, however, these details become important, and we need to incorporate them into our theory. To do this, we look to the liquid state theory.

For simple fluids, the Helmholtz free energy can be expressed as a diagrammatic expansion involving integrals over the Mayer $f$-function [172]. As in the case of simple fluids, the free energy of a molecular fluid can be also expressed in terms of diagrams $[173,174]$. However, the diagrammatic expansion for the molecular fluid contains bonds which correspond to intramolecular bonding interactions, in addition to the Mayer $f$-bonds which describe the interaction between sites not directly bonded to each other.

Summing all diagrams with no intramolecular bonds and a subclass of diagrams with intramolecular bonds with at most one-loop, yields the following approximation 
for the residual Helmholtz free energy $F^{\text {res }}$ of the molecular system

$$
\beta F^{\mathrm{res}}\left(T, c_{\mathrm{p}}\right)=\beta F_{\mathrm{ref}}^{\mathrm{res}}\left(T, N c_{\mathrm{p}}\right)+\frac{V}{2} \int_{q} \ln \left[1-N^{2} \hat{f}(q) c_{\mathrm{p}} H(q)\right]+\cdots,
$$

where $F_{\text {ref }}^{\text {res }}$ is the residual Helmholtz free energy of a disconnected monomer fluid, $\hat{f}(q)$ is the Fourier transform of the Mayer $f$-function, and $H$ is given by

$$
H(q)=\frac{1}{N^{2}} \sum_{a, b=1}^{N}\left(1-\delta_{a b}\right) \hat{s}_{a b}(q),
$$

where $\delta_{a b}$ is the Kronecker delta function, and $\hat{s}_{a b}(q)$ is the Fourier transform of the distribution function between sites $a$ and $b$ in the isolated molecule with no selfinteractions. For a freely joined chain, $\hat{s}_{a b}(q)=[\sin (q l) /(q l)]^{|a-b|}$ where $l$ is the bond length of the chain.

The first term in equation (47) sums over the diagrams with no intramolecular bonds. This term accounts for the details of the monomer-monomer interaction, which become important at high packing fractions. The second term sums all oneloop diagrams with at least one intramolecular bond. This term describes the influence of the bonding interactions. For a disconnected monomer fluid, the second term vanishes, and equation (47) reduces to the residual free energy of a disconnected monomer fluid. In the limit of no monomer-monomer interactions, $f(r)=0$ both the first and the second terms vanish. Therefore, we are left with the free energy of an ideal gas (i.e., $F^{\text {res }}=0$ ) of non-interacting chains.

For large molecules, the function $H(q)$ rapidly approaches zero as $q$ increases, and is nonzero only for very small values of $q$. On the other hand, the function $\hat{f}(q)$ varies slowly with $q$. In this case, the product $\hat{f}(q) H(q)$ is well approximated by $\hat{f}(0) H(q)$. With this replacement, we find

$$
\begin{aligned}
\beta F^{\mathrm{res}}\left(T, c_{\mathrm{p}}\right)= & \beta F_{\mathrm{ref}}^{\mathrm{res}}\left(T, N c_{\mathrm{p}}\right)+\frac{V}{2} c_{\mathrm{p}}^{2} N^{2} \hat{f}(0) \\
& -\frac{V}{2} c_{\mathrm{p}}^{2} N^{2} \hat{f}(0)+\frac{V}{2} \int_{q} \ln \left[1-N^{2} \hat{f}(0) c_{\mathrm{p}} H(q)\right]+\cdots
\end{aligned}
$$

The first two terms on the right-hand side of equation (48) account for the details of the monomer-monomer interactions. These terms are significant only when the monomers occupy a significant fraction of space. At very low monomer concentrations, they vanish. The third and fourth terms are similar to the one-loop expression obtained from the Edwards Hamiltonian [see equation (33)]. In this case, the role of $v_{\mathrm{B}}$ is played by $-\hat{f}(0)$, the role of $S_{\mathrm{B}}$ is played by $N$, and the role of $g_{0}\left(q^{2} S_{\mathrm{B}} / 2\right)$ is played by $H(q)$. This suggests that we can renormalize these terms in a similar manner as in the previous section.

The Mayer $f$-function describes the correlation between two monomers due to direct interactions. The total correlation function describes the correlation between two monomers due to interactions mediated through intermediate monomers in the 


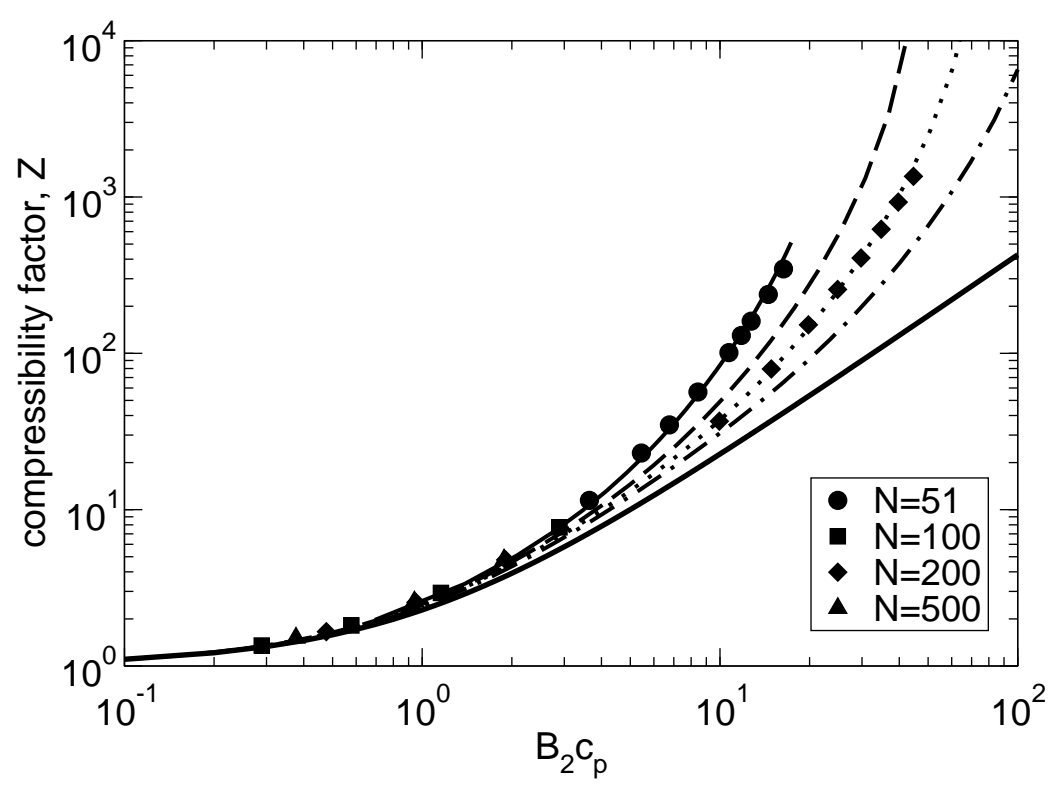

Figure 13. Equation of state of tangent hard-sphere chains in the dilute to concentrated regimes. The symbols are the results of computer simulations for $N=51$ (circles), $N=100$ (squares), $N=200$ (diamonds), and $N=500$ (triangles). The lines are the predictions of equation (50) for: $N=51$ (solid line), $N=100$ (dashed line), $N=200$ (dotted line), $N=500$ (dashed-dotted line), and $N \rightarrow \infty$ (thick solid line).

system, in addition to direct interactions. By replacing the Mayer $f$-function in equation (48) with the total correlation function of the disconnected monomer fluid $\hat{h}_{\text {ref }}(q)$, we can sum over a larger class of diagrams $[175,176]$. Making this substitution and rearranging the terms like in the previous section, the last two terms in equation (48) can be rewritten as

$$
c_{\mathrm{p}} \bar{X} \exp \left[\frac{\Psi}{4 X^{2}}(4 \pi)^{d / 2} \int_{q}\left\{\ln [1+\bar{X} H(q)]-\bar{X} H(q)+\frac{1}{2} \bar{X}^{2} H^{2}(q)\right\}\right],
$$

where $\bar{X}=B_{2} c_{\mathrm{p}} \Gamma_{1}$, and $\Gamma_{1}=\hat{h}_{\text {ref }}(0) / \hat{f}(0)$. Performing the same operations as in the previous section, we find that the final expression for the residual Helmholtz free energy is

$$
\beta F^{\mathrm{res}}\left(T, c_{\mathrm{p}}\right)=\beta F_{\mathrm{ref}}^{\mathrm{res}}\left(T, N c_{\mathrm{p}}\right)+\frac{V}{2} N^{2} \hat{f}(0) c_{\mathrm{p}}^{2}+V c_{\mathrm{p}} \bar{X} \exp \left[-\frac{\Psi}{4 K} A(\bar{X})\right] .
$$

Note that this expression inherently assumes that $\hat{f}(0)<0$, which corresponds to the chains in good solvent conditions.

The equation of state is given by

$$
\begin{aligned}
\frac{\beta \Pi}{c_{\mathrm{p}}}= & +N Z_{\mathrm{ref}}^{\mathrm{res}}\left(T, N c_{\mathrm{p}}\right)+\frac{1}{2} \hat{f}(0) N^{2} c_{\mathrm{p}} \\
& +\bar{X}\left(1+\Gamma_{2}\right)\left[1+\frac{\Psi}{2 K} B(\bar{X})\right] \exp \left[-\frac{\Psi}{4 K} A(\bar{X})\right]
\end{aligned}
$$


where $Z_{\text {ref }}^{\text {res }}$ is the residual compressibility factor for the disconnected monomer fluid, and $\Gamma_{2}=\partial \ln \Gamma_{1} / \partial \ln \left(N c_{\mathrm{p}}\right)$.

In figure 13, we plot the equation of state of tangent hard-sphere chain systems of various molecular weight, from the dilute to concentrated regimes. The symbols are the results of the Monte Carlo simulations, and the lines are the predictions of equation (50). As the molecular weight increases, the compressibility factor approaches a universal function of $B_{2} c_{\mathrm{p}}$, given by the thick dashed line. In the dilute/semidilute regimes, where $y \ll 1$, the compressibility factors for the various polymer systems lie approximately on a single, universal curve. This behaviour is also observed experimentally for polymers in good solvents. As the fraction of space occupied by the monomers increases, the equation of state deviates from the universal curve: as $N$ decreases, the deviation occurs at a lower value of $B_{2} c_{\mathrm{p}}$. As can be seen, the predictions of equation (50) agree well with the simulation data.

\section{Conclusions}

In this work, we present a crossover approach for the prediction of the conformational and thermodynamic behaviour of linear [116,117,163] and star $[118,164]$ polymers in good solvent conditions. In the dilute regime, a critical degree of polymerization $N^{*}$ is found to play a similar role as the Ginzburg number in the crossover theory for critical phenomena in simple fluids [100]. Polymers with $1 \ll N \ll N^{*}$ exhibit Gaussian statistics, and polymers with $N^{*} \ll N$ are in the Kuhnian scaling regime. A crossover from Gaussian statistics to the Kuhnian regime is observed when $N \sim N^{*}$.

We show that for linear and star polymers there are two types of approaches toward the good solvent limit: (i) Gaussian to the Kuhnian, and (ii) semiflexible to the Kuhnian. In both cases, when $N \gg N^{*}$ the system exhibits the Kuhnian scaling behaviour. However, in the type (i) crossover, the penetration function is approached from below (i.e., $\Psi<\Psi^{*}$ ), and in the type (ii), it is approached from above (i.e., $\Psi>\Psi^{*}$ ).

The crossover theory was tested against Monte Carlo simulation data for the structure and thermodynamics of model linear polymers composed of rigidly bonded hard spheres, interacting with a square-well attraction, above and near the theta point. In particular, we discuss our Monte Carlo calculations for the mean-square center-to-end distance, mean-square radius of gyration, and second virial coefficient of $f=3$ to 41 arm star polymers composed of rigidly bonded hard spheres of varying diameters. We show that the crossover theory is in good agreement with the simulation data for star polymers with up to $f=41$ arms. The theory is also able to accurately describe the variation of the infinite molecular weight limit of the penetration function with the number of arms $f$ on the star polymer, and it predicts that $\Psi^{*}$ approaches 2.39 in the limit $f \rightarrow \infty$.

Finally, by combining polymer field theory methods with the liquid state theory, we develop an equation of state for linear [163] and star [164] polymers in good solvents. This equation of state captures the scaling behaviour of polymer solu- 
tions in the dilute/semidilute regimes, and also performs well in the concentrated regimes, where the details of the monomer-monomer interactions become important. We compare this theory to Monte Carlo simulation data for the volumetric behaviour of tangent hard-sphere polymers.

\section{Acknowledgements}

The research at the Colorado School of Mines was supported by the U.S. Department of Energy, Office of Basic Energy Sciences, under Grant No. DE-FG0395ER41568.

\section{References}

1. Roovers J. // Macromolecular simposia., 1997, vol. 121, p. 89-93.

2. Likos C.N., Löwen H., Watzlawek M., Abbas B., Jucknischke O., Allgaier J., Richter D. // Phys. Rev. Lett., 1998, vol. 80, No. 20, p. 4450-4453.

3. Stellbrink J., Allgaier J., Monkendusch M., Richter D., Lang A., Likos C., Watzlawek M., Löwen H., Ehlers G., Schleger P. // Progr. Colloid Polym. Sci., 2000, vol. 115 , p. $88-92$.

4. Roovers J., Zhou L.-L., Toporowski P.M., Van der Zwan M., Iatrou H., Hadjichristidis N. // Macromolecules, 1993, vol. 26, No. 16, p. 4324-4331.

5. Wesley R., Cosgrove T., Thompson L. // Langmuir, 1999, vol. 15, No. 24, p. 83768382.

6. Zhou G.-B., Smid J. // Polymer, 1993, vol. 34, No. 24, p. 5128-5133.

7. Willner L., Juckmischke O., Richter D., Farago D., Fetters L.J., Huang J.S. // Europhys. Lett., 1992, vol. 19, No. 4, p. 297-303.

8. Richter D., Juckmischke O., Willner L., Fetters L.J., Lin M., Huang J.S., Roovers J., Toporski C., Zhou L.-L. // J. de Physique IV, 1993, vol. 3, p. 3-12.

9. Guo A., Liu G., Tao J. // Macromolecules, 1996, vol. 29, p. 2487-2493.

10. Grest G.S., Fetters L.J., Huang J.S., Richter D. // Adv. Chem. Phys., 1996, vol. XCIV, p. 67-163.

11. Gast A.P. // Langmuir, 1996, vol. 12, No. 17, p. 4060-4067.

12. Freire J.J. // Adv. Polym. Sci., 1999, vol. 143, p. 35-112.

13. Douglas J.F., Roovers J., Freed K.F. // Macromolecules, 1990, vol. 23, No. 18, p. $4168-4180$.

14. Shiwa Y., Oono Y., Baldwin P. // Modern Phys. Lett. B, 1990, vol. 4, No. 22, p. $1421-1428$.

15. Ganazzoli F., Allegra G. // Macromolecules, 1990, vol. 23, No. 1, p. 262-267.

16. Ganazzoli F., Fontelos M., Allegra G. // Polymer, 1991, vol. 32, No. 1, p. 170-180.

17. Ganazzoli F. // Macromolecules, 1992, vol. 25, No. 26, p. 7357-7364.

18. Boothroyd A.T., Ball A.C. // Macromolecules, 1990, vol. 23, No. 6, p. 1729-1734.

19. Boothroyd A.T., Fetters L.J. // Macromolecules, 1991, vol. 24, No. 18, p. 5215-5217.

20. Ohno K., Binder K. // J. Chem. Phys., 1991, vol. 95, No. 7, p. 5444-5458.

21. Ohno K., Binder K. // J. Chem. Phys., 1991, vol. 95, No. 7, p. 5459-5473.

22. Yethiraj A., Hall C.K. // J. Chem. Phys., 1991, vol. 94, No. 5, p. 3943-3948.

23. Halperin A., Joanny J.F. // J. de Physique II, 1991, vol. 1, No. 6, p. 623-636. 
24. Raphael E., Pincus P., Fredrickson G.H. // Macromolecules, 1993, vol. 26, No. 8, p. 1996-2006.

25. Merkle G., Burchard W., Lutz P., Freed K.F., Gao J. // Macromolecules, 1993, vol. 26, No. 11, p. 2736-2742.

26. Guenza M., Perico A. // Macromolecules, 1993, vol. 26, No. 16, p. 4196-4202.

27. Zhu S. // Macromolecules, 1998, vol. 31, No. 21, p. 7519-7527.

28. Garas G., Kosmas M. // Macromolecules, 1994, vol. 27, No. 22, p. 6671-6672.

29. Stepanova T.A., Stekolnikov A.V. // Mol. Phys., 1994, vol. 83, No. 6, p. 1065-1089.

30. Jagodzinski O. // J. Phys. A: Math. Gen., 1994, vol. 27, p. 1471-1494.

31. Irvine D.J., Mayes A.M., Griffith-Cima L. // Macromolecules, 1996, vol. 29, No. 18, p. 6037-6043.

32. Dondos A., Papanagopoulos D. // Polymer, 1997, vol. 38, No. 25, p. 6255-6258.

33. Groh B., Schmidt M. // J. Chem. Phys., 2001, vol. 114, No. 12, p. 5250-5436.

34. Freire J.J., Pla J., Rey A., Prats R. // Macromolecules, 1986, vol. 19, No. 2, p. 452457.

35. Rey A., Freire J.J., Bishop M., Clarke J.H.R. // Macromolecules, 1992, vol. 25, No. 4, p. $1311-1315$.

36. Zifferer G. // Makromol. Chem. Theory Simul., 1993, vol. 2, No. 5, p. 653-671.

37. Zifferer G. // Makromol. Theory Simul., 1999, vol. 8, No. 5, p. 433-462.

38. Allegra G., De Vitis M., Ganazzoli F. // Makromol. Chem. Theory Simul., 1993, vol. 2, No. 6, p. 829-849.

39. Sikorski A. // Polymer, 1993, vol. 34, No. 6, p. 1271-1281.

40. Romiszowski P., Sikorski A. // J. Chem. Phys., 1998, vol. 109, No. 7, p. 2912-2920.

41. Sikorski A., Romiszowski P. // J. Chem. Phys., 1998, vol. 109, No. 14, p. 6169-6174.

42. Zhao D., Lookman T. // Europhys. Lett., 1994, vol. 26, No. 5, p. 339-343.

43. Grest G.S. // Macromolecules, 1994, vol. 27, No. 13, p. 3493-3500.

44. Ohno K. // Die Makromol. Chemie. Macromolecular simposium., 1994, vol. 81, p. 121.

45. Ohno K., Shida K., Kimura M., Kawazoe Y. // Macromolecules, 1996, vol. 29, No. 6, p. 2269-2274.

46. Shida K., Ohno K., Kimura M., Kawazoe Y. // J. Chem. Phys., 1996, vol. 105, No. 19, p. 8229-8936.

47. Shida K., Ohno K., Kimura M., Kawazoe Y. // Macromolecules, 2000, vol. 33, No. 20, p. $7655-7662$.

48. Shida K., Ohno K., Kimura M., Kawazoe Y. // Comput. Theor. Polym. Sci., 2000, vol. 10, No. 3-4, p. 281-285.

49. Bishop M., Clarke J.H.R., A.R., Freire J.J. // J. Chem. Phys., 1991, vol. 94, No. 5, p. 4009-4011.

50. Bishop M., Clarke J.H.R., Freire J.J. // J. Chem. Phys., 1995, vol. 102, No. 12, p. 5094-5099.

51. Zifferer G. // Macromol. Theory Simul., 1996, vol. 5, No. 4, p. 759.

52. Zhang L. // Polymer Journal, 1996, vol. 28, No. 6, p. 471-473.

53. Forni F., Ganazzoli F., Vacatello M. // Macromolecules, 1996, vol. 29, p. 2994-2999.

54. Forni A., Ganazzoli F., Vacatello M. // Macromolecules, 1997, vol. 30, p. 4737-4743.

55. Rubio A.M., Freire J.J. // Macromolecules, 1996, vol. 29, No. 21, p. 6946-6951.

56. Rubio A.M., Freire J.J. // Comput. Theor. Polym. Sci., 2000, vol. 10, p. 89-96.

57. Grassberger P. // Phys. Rev. E, 1997, vol. 56, p. 3682-3693. 
58. Watzlawek M., Löwen H., Likos C.N. // J. Phys.: Condens. Matter, 1998, vol. 10, No. 37, p. 8189-8205.

59. Watzlawek M., Likos C.N., Löwen H. // Phys. Rev. Lett., 1999, vol. 82, No. 26, p. $5289-5292$.

60. Toma L., Toma S., Subirana J.A. // Macromolecules, 1998, vol. 31, No. 7, p. 23282334.

61. Rassell T.P., Fetters L.J., Clark J.C., Bauer B.J., Han C.C. // Macromolecules, 1990, vol. 23, No. 2, p. 654-659.

62. Roovers J., Toporowski P.M., Douglas J. // Macromolecules, 1995, vol. 28, No. 21, p. 7064-7070.

63. Okumoto M., Terao K., Nakamura Y., Norisuye T., Teramoto A. // Macromolecules, 1977, vol. 30, No. 24, p. 7493-7499.

64. Ishizu K., Ono T., Uchida S. // Macromol. Chem. Phys., 1997, vol. 198, p. 3255-3265.

65. Okumoto M., Nakamura Y., Norisuye T., Teramoto A. // Macromolecules, 1998, vol. 31, No. 5, p. 1615-1620.

66. Jusufi A., Watzlawek M., Löwen H. // Macromolecules, 1999, vol. 32, No. 13, p. 44704473.

67. Striolo A., Prausnitz J.M., Bertucco A. // Macromolecules, 2000, vol. 33, No. 26, p. 9583-9586.

68. Striolo A., Prausnitz J.M. // J. Chem. Phys., 2000, vol. 113, No. 7, p. 2927-2931.

69. Terao K., Okumoto M., Nakamura Y., Norisuye T., Teramoto A. // Macromolecules, 1998, vol. 31, No. 20, p. 6885-6890.

70. Richter D., Farago B., Fetters L.J. // Macromolecules, 1990, vol. 23, No. 6, p. 18451856.

71. Ewen B., Righter D., Fetters L.J. // J. Non-Crystline Solids, 1991, vol. 131/133, No. 2, p. 697-702.

72. Guenza M., Mormino M., Perico A. // Macromolecules, 1991, vol. 24, No. 23, p. 61686174.

73. Guenza M., Perico A. // Macromolecules, 1992, vol. 25, No. 22, p. 5942-5949.

74. Guenza M., Perico A. // Die Makromol. Chemie. Macromolecular simposium., 1994, vol. 81, p. 115 .

75. Sikorski A. // Macromol. Chem. Theory Simul., 1993, vol. 2, No. 3, p. 309-318.

76. Sikorski A., Kolinski A., Skolnik J. // Macromol. Theor. Simul., 1994, vol. 3, No. 4, p. $715-729$.

77. Shida K., Ohno K., Kimura M., Kawazoe Y., Nakamura Y. // Macromolecules, 1998, vol. 31, No. 7, p. 2343-2348.

78. Stellbrink J., Abbas B., Watzlawek M. // Progr. Colloid Polym. Sci., 1998, vol. 110, p. 25.

79. Factor B.J., Russell T.P., Smith B.A. // Macromolecules, 1990, vol. 23, No. 20, p. $4452-4455$.

80. Vlassopoulos D., Pakula T., Fytas G., Pistikalis M., Hadjichristidis N. // J. Chem. Phys., 1999, vol. 111, No. 4, p. 1760-1764.

81. Grest G.S., Kremer K., Milner S.T., Witten T.A. // Macromolecules, 1989, vol. 22, No. 4, p. 1904-1910.

82. Su S.-J., Denny S., Kovac J. // Macromolecules, 1991, vol. 24, No. 4, p. 917-923.

83. Su S.-J., Kovac J. // J. Chem. Phys., 1992, vol. 96, No. 10, p. 3931-3934.

84. Wiegel B., Strating P. // Int. J. Modern Phys. B, 1994, vol. 8, No. 8, p. 1081. 
85. Sikorski A., Romiszowski P. // Macromol. Theory Simul., 1999, vol. 8, No. 2, p. 103.

86. Ganazzoli F., Allegra G., De Vitis M. // Macromolecules, 1995, vol. 28, No. 4, p. $1076-1084$.

87. Ganazzoli F., Forni A. // Macromolecules, 1995, vol. 28, No. 23, p. 7950-7952.

88. Gannazzoli F., Raffaini G. // Macromol. Theory Simul., 1999, vol. 8, No. 3, p. 234.

89. Shull K.R., Kramer E.J., Fetters L.J. // Nature, 1990, vol. 345, No. 6278, p. 790-791.

90. Easwar N., Langley K., Karasz F. // Macromolecules, 1990, vol. 23, No. 3, p. 738-745.

91. Lodge T.P., Rotstein N.A. // J. Non-Crystline Solids, 1991, vol. 131/133, No. 2, p. $671-675$.

92. Levine A.J., Milner S.T. // Macromolecules, 1999, vol. 32, No. 3, p. 911-914.

93. Fleischer G., Fytas G., Hadjichristidis N. // Physica A, 2000, vol. 280, No. 3/4, p. 266.

94. Fetters L.J., Andrea D., Pearson D.S. // Macromolecules, 1993, vol. 26, No. 4, p. 647645.

95. Levine A.J., Milner S.T. // Macromolecules, 1998, vol. 31, No. 24, p. 8623-8637.

96. Gell C.B., Graessley W.W., Efstratiadis V., Pitsikalis M., Hadjichristidis N. // J. Polymer Sci. B, 1997, vol. 35, No. 12, p. 1943-1954.

97. Phillies G.D. // J. Chem. Phys., 1999, vol. 110, No. 12, p. 5989-5992.

98. Phillies G.D. // J. Chem. Phys., 1999, vol. 111, No. 17, p. 8144-8119.

99. Stellbrink J., Allgaier J., Richter D. // Phys. Rev. E, 1997, vol. 56, No. 4, p. R3772R3775.

100. Belyakov M.Y., Kiselev S.B. // Physica A, 1992, vol. 190, p. 75-94.

101. Anisimov M.A., Kiselev S.B., Sengers J.V., Tang S. // Physica A, 1992, vol. 188, p. $487-525$.

102. Kiselev S.B., Povodyrev A.A. // High Temp., 1996, vol. 34, No. 4, p. 621-639.

103. Kiselev S.B. // Fluid Phase Equil., 1997, vol. 128, p. 1-28.

104. Kiselev S.B., Rainwater J.C. // J. Chem. Phys., 1998, vol. 109, No. 2, p. 643-657.

105. Kiselev S.B., Abdulagatov I.M., Harvey A.H. // Int. J. Thermophys., 1999, vol. 20, No. 2, p. $563-588$.

106. Kostrowicka Wysczalkowska A., Sengers J.V. // J. Chem. Phys., 1999, vol. 111, No. 4, p. $1551-1560$.

107. Kostrowicka Wysczalkowska A., Abdulkadirova K.S., Anisimov M.A., Sengers J.V. // J. Chem. Phys., 2000, vol. 113, No. 12, p. 4985-5002.

108. Belyakov M.Y., Kiselev S.B., Rainwater J.C. // J. Chem. Phys., 1997, vol. 107, No. 8, p. $3085-3097$.

109. Jacob J., Kumar A., Anisimov M.A., Povodyrev A.A., Sengers J.V. // Phys. Rev. E, 1998, vol. 58, No. 2, p. 2188-2200.

110. Gutkowski K., Anisimov M.A., Sengers J.V. // J. Chem. Phys., 2001, vol. 114, No. 7, p. 3133-3148.

111. Schwahn D., Mortensen K., Janssen S. // Phys. Rev. Lett., 1995, vol. 73, No. 10, p. $1452-1455$.

112. Schwahn D., Schmachers T., Mortensen K. // Phys. Rev. E, 1995, vol. 52, No. 2, p. R1288-R1291.

113. Frielinghaus H., Schwahn D., Mortensen K., Willner L., Almdal K. // Physica B, 1997, vol. 234-236, p. 260-262.

114. Melnichenko Y.B., Anisimov M.A., Povodyrev A.A., Wignall G.D., Sengers J.V., Van Hook W.A. // Phys. Rev. Lett., 1997, vol. 79, No. 26, p. 5266-5269. 
115. Seto H., Schwahn D., Yokoi E., Nagao M., Komura S., Imai M., Mortensen K. // Physica B., 1995, vol. 213/214, p. 591-593.

116. Lue L., Kiselev S.B. // J. Chem. Phys., 1999, vol. 110, No. 5, p. 2684-2691.

117. Lue L., Kiselev S.B. // J. Chem. Phys., 1999, vol. 111, No. 12, p. 5580-5592.

118. Lue L., Kiselev S.B. // J. Chem. Phys., 2001, vol. 114, No. 11, p. 5026-5033.

119. Rey A., Freire J.J., Clarke J.H.R., Yong C.W., Bishop M. // Macromolecules, 1987, vol. 20, p. 342.

120. de Gennes P.-G. Scaling Concepts in Polymer Physics. Ithaca, Cornell, 1979.

121. Grosberg A., Khokhlov A. Statistical Physics of Macromolecules. AIP Series in Polymers and Complex Materials. New York, AIP Press, 1994.

122. Rudnick J., Gaspari G. // J. Phys. A: Math. Gen., 1986, vol. 19, No. 4, p. L191-L193.

123. Aronovitz J.A., Nelson D.R. // J. Phys. (France), 1986, vol. 47, No. 9, p. 1445-1456.

124. Wei G.Y., Eichinger B.E. // J. Chem. Phys., 1990, vol. 93, p. 1430-1435.

125. Batoulis J., Kremer K. // Macromolecules, 1989, vol. 22, No. 11, p. 4277-4285.

126. Bishop M., Clarke J.H.R. // J. Chem. Phys., 1989, vol. 91, No. 6, p. 3721-3723.

127. Daoud M., Cotton J.P. // J. Phys. (Paris), 1982, vol. 43, No. 3, p. 531-538.

128. Zimm B.H., Stockmayer W.H. // J. Chem. Phys., 1949, vol. 17, p. 1301.

129. Miyake A., Freed K.F. // Macromolecules, 1983, vol. 16, p. 1228-1241.

130. Grest G.S., Kremer K., Witten T.A. // Macromolecules, 1987, vol. 20, No. 6, p. 13761383.

131. Guillou J.C.L., Zinn-Justin J. // Phys. Rev. Lett., 1977, vol. 39, No. 2, p. 95-98.

132. de Gennes P.G. // Phys. Lett. A, 1972, vol. 38, p. 339.

133. Bishop M., Clarke J.H.R. // J. Chem. Phys., 1989, vol. 91, No. 11, p. 6647-6651.

134. Boothroyd A.T., Squires G.L., Fetters L.J., Rennie A.R., Horton J.C., de Vallera A.M.B.G. // Macromolecules, 1989, vol. 22, No. 7, p. 3130-3139.

135. Horton J.C., Squires G.L., Boothroyd A.T., Fetters L.J., Rennie A.R., Glinka C.J., Robinson R.A. // Macromolecules, 1989, vol. 22, No. 2, p. 681-686.

136. Douglas J.F., Freed K.F. // Macromolecules, 1984, vol. 17, p. 1854-1870.

137. Cotton J.P. // J. Phys. Lett. France, 1988, vol. 41, p. 231.

138. Nickel B.G. // Macromolecules, 1991, vol. 24, No. 6, p. 1358-1365.

139. Yamakawa H., Abe F., Einaga Y. // Macromolecules, 1993, vol. 26, p. 1898-1904.

140. Tanaka G. // J. Polym. Sci., Part A-2, 1979, vol. 17, p. 305.

141. Tanaka G. // Macromolecules, 1982, vol. 15, No. 6, p. 1525-1527.

142. Fujita H. Polymer Solutions. Elsevier, Amsterdam, 1990.

143. Huber K., Stockmayer W.H. // Macromolecules, 1987, vol. 20, No. 6, p. 1400-1402.

144. Roovers J., Hadjichristidis N., Fetters L.J. // Macromolecules, 1983, vol. 17, No. 2, p. 214-220.

145. Huber K., Burchard W., Fetters L.J. // Macromolecules, 1984, vol. 17, No. 4, p. 541548.

146. Toporowski P.M., Roovers J. // J. Polym. Sci., Polym. Chem. Ed., 1986, vol. 24, No. 11, p. 3009-3019.

147. Li B., Madras N., Sokal A. // J. Stat. Phys., 1995, vol. 80, No. 3/4, p. 661-754.

148. Schäfer L. // Phys. Rev. E, 1994, vol. 50, No. 5, p. 3517-3525.

149. Krüger B., Schäfer L. // J. Phys. I France, 1994, vol. 4, p. 757-790.

150. Krüger B., Schäfer L. // Macromolecules, 1996, vol. 29, p. 4737-4744.

151. Grassberger P., Sutter P., Schäfer L. // J. Phys. A: Math. Gen., 1997, vol. 30, p. 70397056 . 
152. Bruns W., Carl W. // Macromolecules, 1991, vol. 24, No. 1, p. 209-212.

153. Bauer B.J., Hadjichristidis N., Fetters L.J., Roovers J.E. // J. Am. Chem. Soc., 1980, vol. 102 , p. 2410.

154. Zhou L.-L., Hadjichistidis N., Toporowski P.M., Roovers J. // Rubber Chem. Tech., 1992, vol. 65, p. 303-314.

155. Likos C.N., Lowen H., Poppe A., Wilner L., Roovers J., Cubitt B., Richter D. // Phys. Rev. E, 1998, vol. 58, No. 5, p. 6299-6307.

156. Edwards S.F. // Proc. Phys. Soc., 1965, vol. 85, p. 613-624.

157. Edwards S.F. // Proc. Phys. Soc., 1966, vol. 88, p. 265-280.

158. Freed K.F. // J. Chem. Phys., 1983, vol. 79, p. 6357-6371.

159. Freed K.F. Renormalization Group Theory of Macromolecules. New York, John Wiley and Sons, 1987.

160. des Cloizeaux J., Jannink G. Polymers in Solution: Their Modelling and Structure. Oxford, Clarendon Press, 1990.

161. Ohta T., Oono Y. // Phys. Lett., 1982, vol. 89A, No. 9, p. 460-464.

162. Cherayil B.J., Bawendi M.G., Miyake A., Freed K.F. // Macromolecules, 1986, vol. 19, No. 19, p. 2770-2778.

163. Lue L. // J. Chem. Phys., 2000, vol. 112, No. 7, p. 3442-3449.

164. Patrickios C.S., Lue L. // J. Chem. Phys., 2000, vol. 113, No. 13, p. 5485-5492.

165. Schäfer L. // Phys. Rep., 1998, vol. 301, p. 205-234.

166. Burchard W. // Adv. Polym. Sci., 1999, vol. 143, p. 113-194.

167. Carnahan N.F., Starling K.E. // J. Chem. Phys., 1969, vol. 51, No. 2, p. 635-636.

168. Wertheim M.S. // J. Chem. Phys., 1987, vol. 87, No. 12, p. 7323-7331.

169. Ghonasgi D., Chapman W.G. // J. Chem. Phys., 1994, vol. 100, No. 9, p. 6633-6639.

170. Chang J., Sandler S.I. // Chem. Eng. Sci., 1994, vol. 49, No. 17, p. 2777-2791.

171. Flory P.J. Principles of Polymer Chemistry. Ithaca, Cornell, 1953.

172. Stell G. - In: Statistical Mechanics: Part A. Equilibrium Techniques. New York, Plenum, 1977.

173. Ladanyi B.M., Chandler D. // J. Chem. Phys., 1975, vol. 62, No. 11, p. 4308-4324.

174. Pratt L., Chandler D. // J. Chem. Phys., 1977, vol. 66, No. 2, p. 147-151.

175. Morita T., Hiroike K. // Progr. Theor. Phys., 1961, vol. 25, p. 537.

176. Stell G. - In: The Equilibrium Theory of Classical Fluids. Editors Frisch H.L., Lebowitz J.L. New York, Benjamin, 1964, p. II 171. 


\title{
Зіркові полімери в добрих розчинниках від розведеного до концентрованого режимів: кросоверний підхід
}

\author{
Л.Лю ${ }^{1}$, С.Б.Кісєльов ${ }^{2}$
}

1 Факультет хімічної технології, UMIST, Манчестер M60 1QD, Великобританія

2 Факультет хімічної технології, Гірнича школа Колорадо, 1500 Іллінойс Ст., Голден, СО 80401-1887, США

\section{Отримано 12 вересня 2001 р.}

Подано вступ до кросоверної теорії конформаційних і термодинамічних властивостей зіркових полімерів у добрих розчинниках. Кросоверну теорію перевірено порівнянням з даними Монте Карло обчислень структурних і термодинамічних властивостей моделі зіркових полімерів. В умовах доброго розчинника властивості зіркових полімерів прямують до "універсальної” границі $N \rightarrow \infty$; однак, є два різних способи прямування до цієї границі. В розведеному режимі, критичний ступінь полімеризації $N^{*}$ відіграє таку ж роль, як число Гінзбурга в теорії кросоверу в простих рідинах. Функція проникнення визначає вільну енергію розчинів зіркових полімерів в розведеній і напіврозведеній ділянках. Це рівняння стану описує основні риси скейлінгової поведінки полімерних розчинів в розведеному/напіврозведеному режимах і добре працює також в концентрованому режимі, де стають важливими деталі взаємодії між мономерами.

Ключові слова: зірковий полімер, комп'ютерна симуляція, ренормалізаційна група, полімерна теорія поля

PACS: $61.25 . \mathrm{Hq}$ 